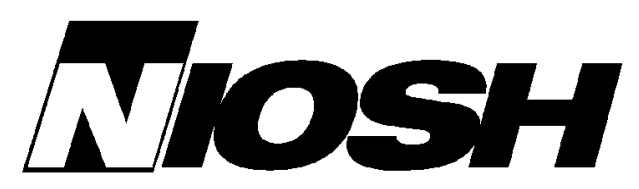

RI 9644

REPORT OF INVESTIGATIONS/1998

\title{
Model for the Structure of Round-Strand Wire Ropes
}
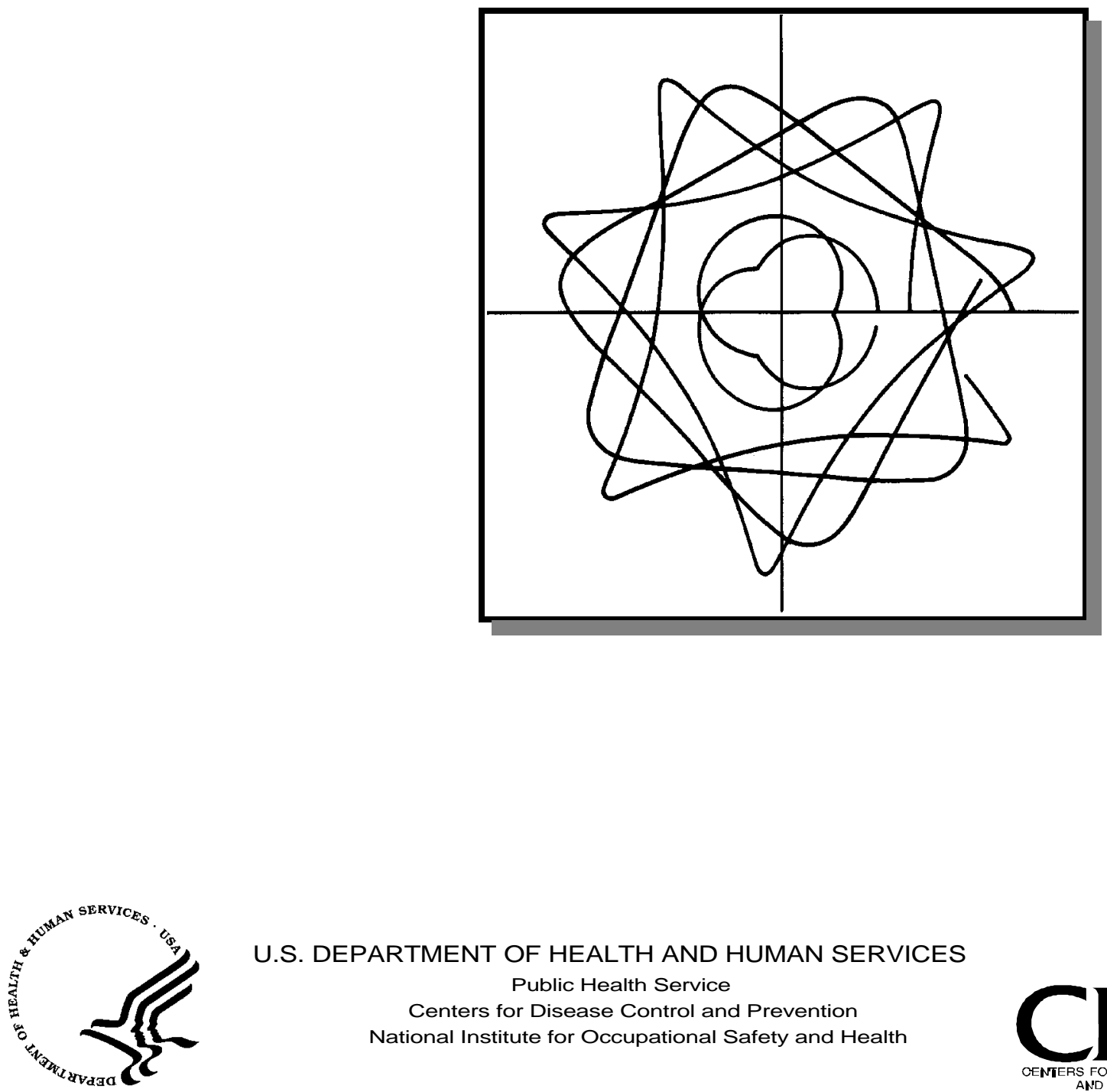

U.S. DEPARTMENT OF HEALTH AND HUMAN SERVICES Public Health Service

Centers for Disease Control and Prevention National Institute for Occupational Safety and Health

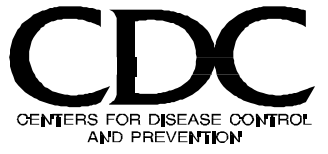


Cover: Paths of three types of double helical wires in a $6 \times 19$ Seale, IWRC, right regular lay wire rope looking down the rope axis. 

Report of Investigations 9644

Model for the Structure of Round-Strand Wire Ropes

Richard C. Wang, Anthony J. Miscoe, and William M. McKewan

U.S. DEPARTMENT OF HEALTH AND HUMAN SERVICES

Public Health Service

Centers for Disease Control and Prevention

National Institute for Occupational Safety and Health

Pittsburgh Research Laboratory

Pittsburgh, PA

September 1998 
International Standard Serial Number ISSN 1066-5552 


\section{CONTENTS}

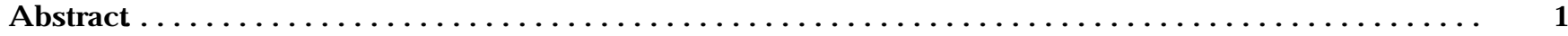

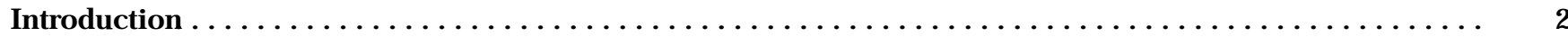

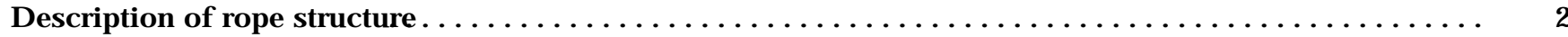

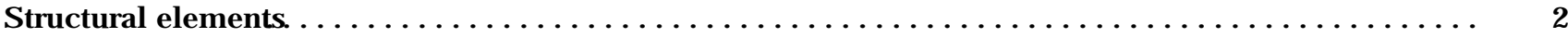

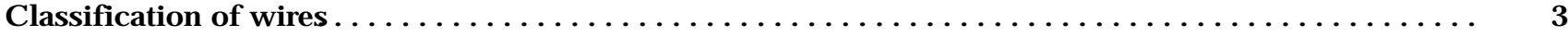

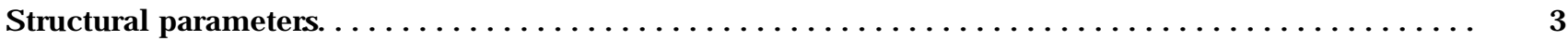

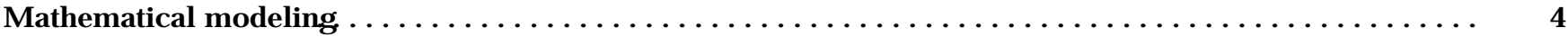

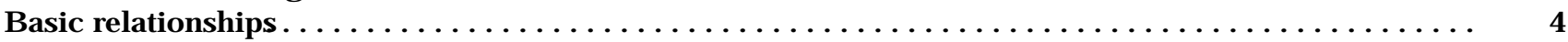

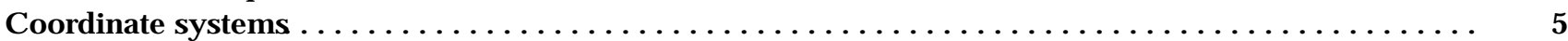

Vector equations for single and double helices. $\ldots \ldots \ldots \ldots \ldots \ldots$

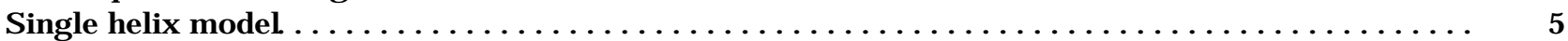

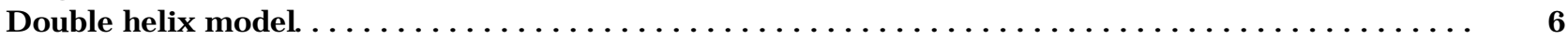

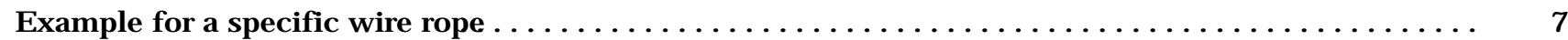

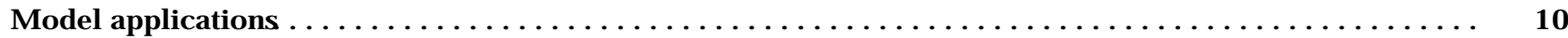

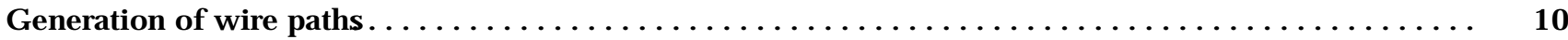

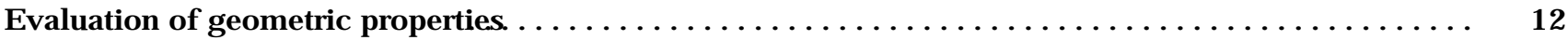

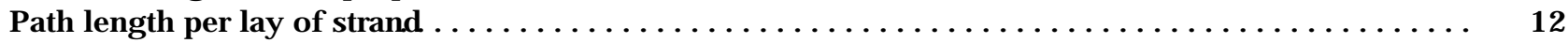

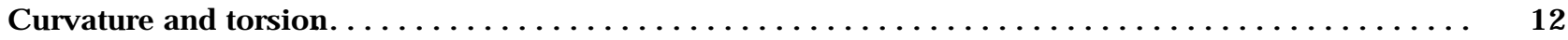

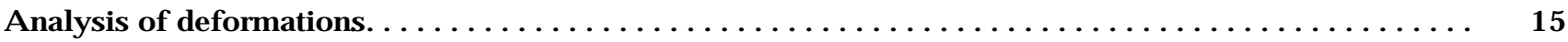

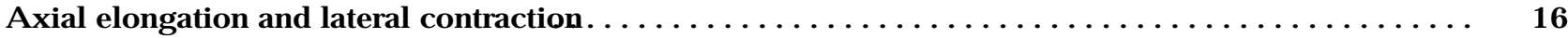

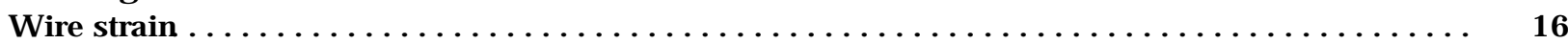

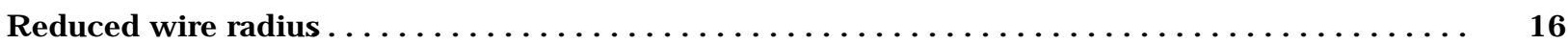

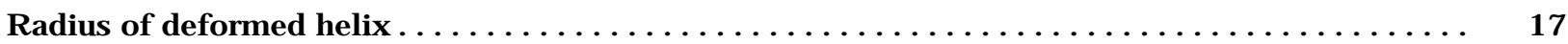

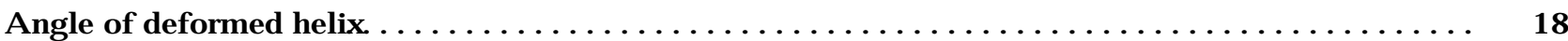

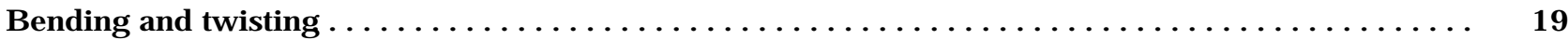

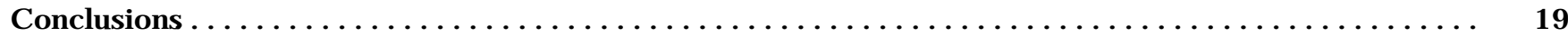

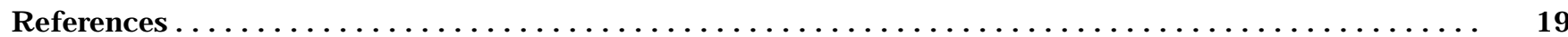

\section{ILLUSTRATIONS}

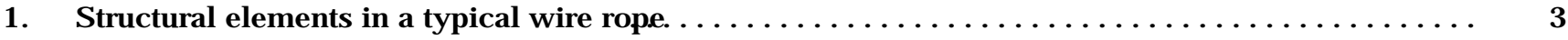

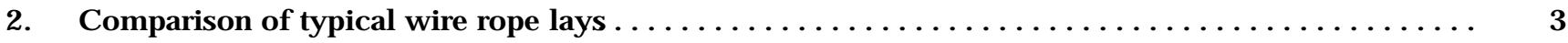

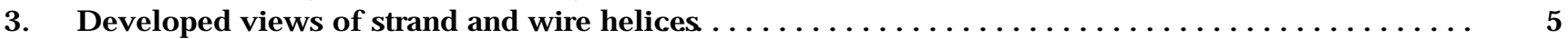

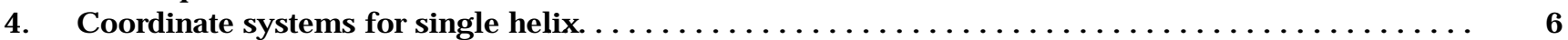

5. Coordinate system for double helix. . . . . . . . . . . . . . . . . . . . . . .

6. Strand arrangement of $33-\mathrm{mm} 6 \times 19$ Seale, IWRC, right regular lay wire.rope $\ldots \ldots \ldots$

7. Cross section of IWRC strand $\mathrm{S} 1 \ldots \ldots \ldots \ldots \ldots \ldots$

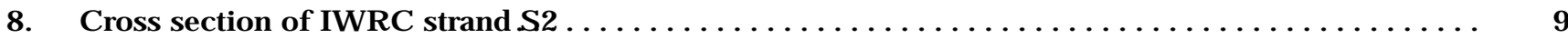

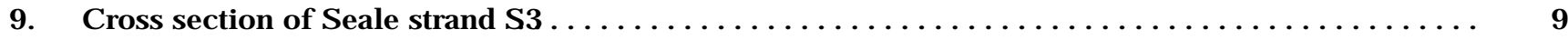

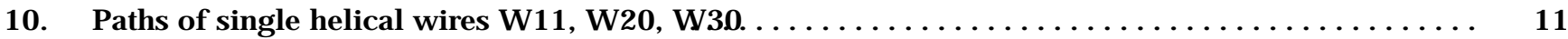

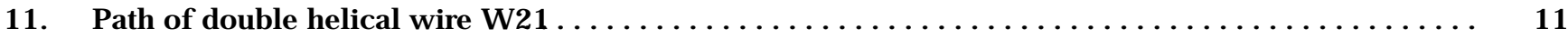

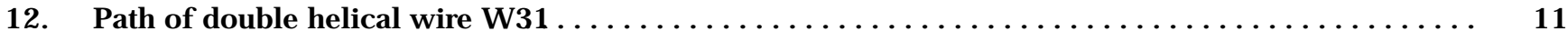

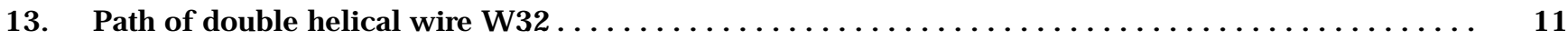

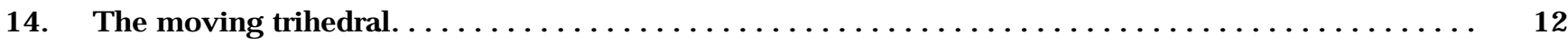

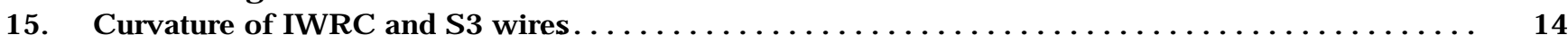

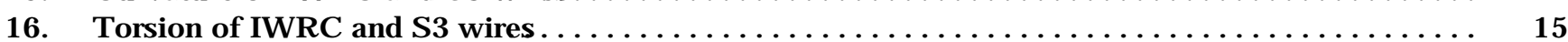


1. Structural parameters of strands in $33-\mathrm{mm} 6 \times 19$ Seale wire.rope. . . . . . . . . . . . . 8

2. Structural parameters of wires in $33-\mathrm{mm} 6 \times 19$ Seale wire rope. . . . . . . . . . . . .

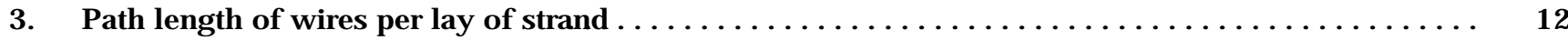

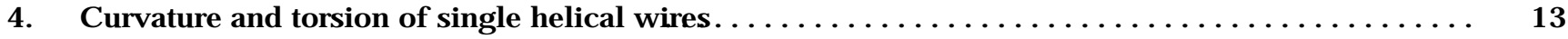

5. Curvature and torsion of double helical wires $\ldots \ldots \ldots \ldots \ldots \ldots$

\section{UNIT OF MEASURE ABBREVIATIONS USED IN THIS REPORT}

$\begin{array}{llll}\mathrm{kPa} & \text { kilopascal } & \text { psi } & \text { pound (force) per square inch } \\ \mathrm{lb} & \text { pound } & \text { rad } & \text { radian } \\ \mathrm{mm} & \text { millimeter } & \circ \text { or deg } & \text { degree } \\ \mathrm{N} & \text { newton } & & \end{array}$

\section{SYMBOLS USED IN THIS REPORT}

\section{Vectors}

b unit binormal vector

$\mathbf{f}, \mathbf{g}, \mathbf{h}$ unit vectors in strand coordinate system

$\mathbf{i}, \mathbf{j}, \mathbf{k}$ unit vectors in rope coordinate system

n unit principal normal vector

P vector that traces double helix in rope coordinate system
Q vector that traces single helix in strand coordinate system

q vector that traces wire rotation and lies on U-V plane

$\mathbf{R}$ vector that traces single helix in rope coordinate system

t unit tangent vector 


\section{Other Symbols}

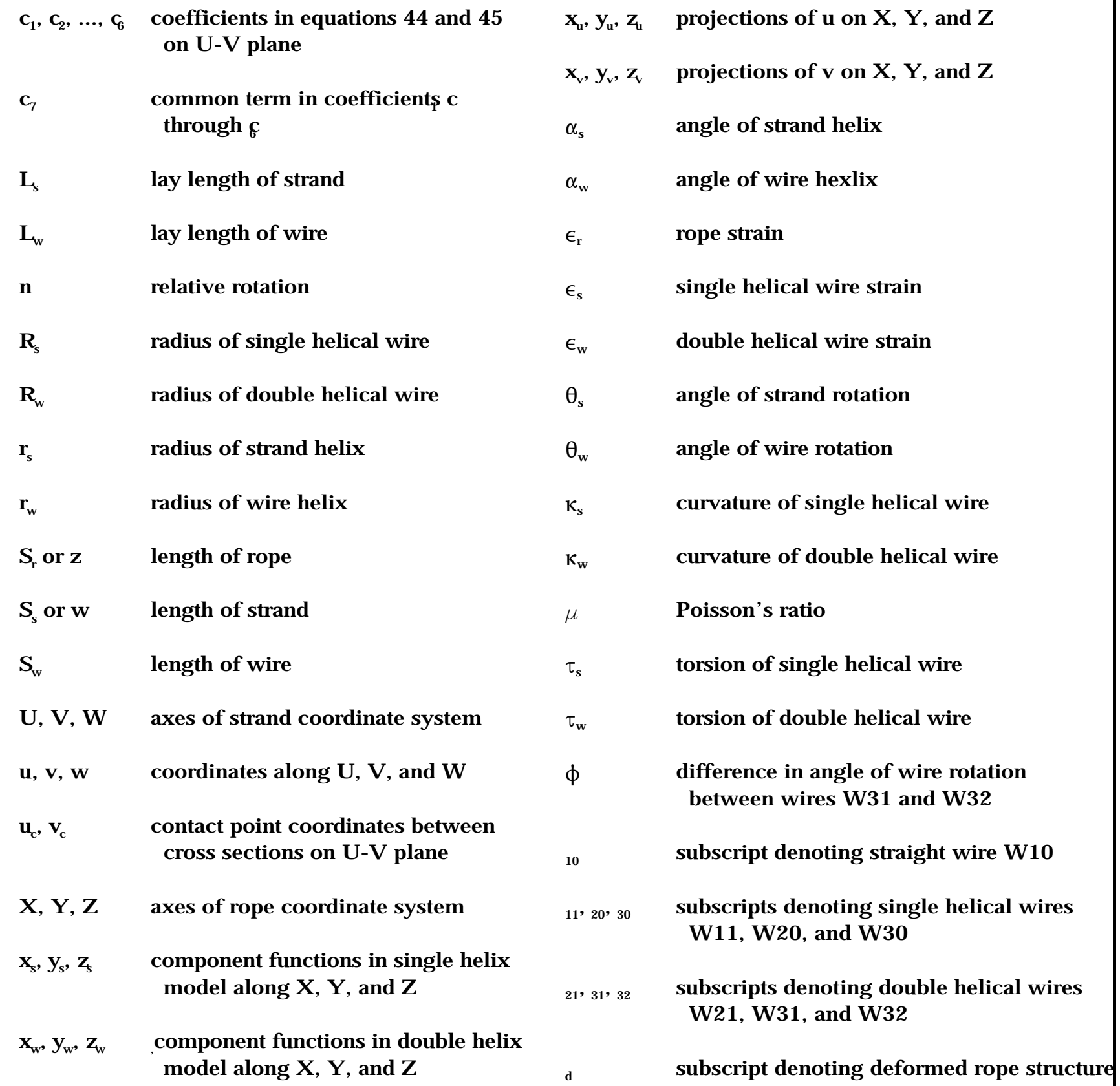

Mentionof any company name or product does not constitute endorsement by the National Institute for Occupational Safety and Health.

Toreceive other information about occupational safety and health problems, call 1-800-35-NIOSH (1-800-356-4674), or visit the NIOSH Home Page on the World Wide Web at http://www.cdc.gov/niosh 


\title{
MODEL FOR THE STRUCTURE OF ROUND-STRAND WIRE ROPES
}

\author{
By Richard C. Wang, ${ }^{1}$ Anthony J. Miscoe, ${ }^{2}$ and William M. McKewan ${ }^{3}$
}

\begin{abstract}
The behavior of wire ropes used in hoisting is not well understood. In an effort to improve this understandingthe structure of round-strand wire ropes was analyzed. This report provides a generalized mathematical model that completely describes the geometry of the wicessi\$ts of two sets of vector equationsand is valid for any round-strand wire rope. One set of equations is used to trace the paths of wires that have the form of a single helix; the other is used for the paths of double helical wires. The specific model for a 33-mm $6 \times 19$ Seale, independent wire rope core (IWRC), right regular lay wire rope was presentedas an example. The paths and the geometric properties of the wires, which include the path length per lay of strand, the curvature, and the torsion, were determined from this model. The effects of strain deformation were analyzed, resulting in a system of equafiodstermining the structural parameters of the deformed rope. In future work, the model could be used to analyze wire ropes of different constructions so that a more scientifically based understanding of rope behavior can be established.
\end{abstract}

\footnotetext{
${ }^{1}$ Mechanical engineer.

${ }^{2}$ Mechanical engineer (retired).

${ }^{3}$ Physical scientist.

Pittsburgh Research Laboratory, National Institute for Occupational Safety and Health, Pittsburgh, PA.
} 


\section{INTRODUCTION}

Wire ropes are used for transmitting tensile forces. The main characteristics that make them so well suited to this function are flexibility and strength. Wire ropes are used in many applications involving the safety of people, such as elevators, ski tows, and cranes. In mine hoisting systems, wire rope is used to transport personnel, product, and supplies between surface and underground. The condition of the rope deteriorates during use due to fatigue, wear, and corrosion. Because the failure of a wire rope can be catastrophic, periodic inspection is needed so that the decision can be made as to whether the rope should be retired.

Mine safety research has long been concerned with improvinghe understanding of rope behavior to forestall the hazardous use of a degraded rope, yet prevent the uneconomical, premature retirement of still-useful rope. Becausthere is widespread disagreement among specialists withregard to the indicators and methods now used to assess hoistrope condition, the National Institute for Occupational SafetyandHealth (NIOSH), Pittsburgh ResearchLaboratory, studiedthe factors responsible for the degradation of hoist ropesso that a better understanding of rope performance can be developed.

The current Federal retirement criteria for wire ropes used in mine hoisting specify the allowable reductions of ropediameter and outside wire diameter and the location and number of broken wires [30 CFR ${ }^{4}$ 56.19024, 57.19024, 75.143477.1434(1997)]. However, their effects on strength loss for ropes of different constructions have not been properly consideredThis will lead to removing wire ropes from service at different stages where the actual loss of strengthis either less or more than what is anticipated. To remedythis deficiency, the knowledge of how the total load is distributed among the wires in different rope constructions needs to be acquired. In general, the load distribution is dependent not only on theross-sectional area of wires, but also on the specific arrangement of wires in a rope.
The wire stresses in an independent wire rope core (IWRC) were compared by Costello [1990]. It was found that,for $17,379 \mathrm{~N}(3,907 \mathrm{lb})$ of load applied to the IWRC, the normal stress was $310,264 \mathrm{kPa}(45,000 \mathrm{psi})$ in the central wire of the center strand and $279,196 \mathrm{kPa}(40,494 \mathrm{psi})$ in the centralwire of the outside strand. They were not only significantly different, but also considerably higher than 247,591 $\mathrm{kPa}(35,910 \mathrm{psi})$, the nominal streomputed by taking the total load and dividing it by the total metallic area. It is thereforebelieved that the load distribution must be considered for different rope constructions to prevent catastrophic failure of ropes in service. To do this, an understandingof the wire geometry that affects the load distribution musfirst be acquired. Although mathematical models have been used to study wire geometry by many researchersin the past, these models can be used only for single helical wires. Lee [1991] presented two sets of Cartesiancoordinate equations in matrix form for double helical wires, but did not give detailed derivation of the equations. One set of the equations was for regular lay ropes; the other was for lang lay ropes.

In this study, the rope structure was analyzed, and a generalizedmathematical model describing the wire geometry in any rope construction with round strands was developed. The modelcontains a rotation ratio, termed "relative rotation" in this report, which characterizes the relationship between the wireand the strand helices. In the use of rope with the ends restrained from rotating, this relative rotation remains constant,thus reducing the parameters in the models to the angle of wire rotation only. The model is general enough that any combination of wire and strand lay directions can be handledif the stated sign conventions for the angles of strand and wire rotation and the relative rotation are followed.

\section{DESCRIPTION OF ROPE STRUCTURE}

\section{STRUCTURAL ELEMENTS}

A wire rope is a structure composed of many individual wires. A typical wire rope is composed of two major structural elements, as shown in figure 1 . One is the strand that is formed byhelically winding or laying wires around a central wire or a strand core. Different shapes of strand may be formeddepending on the shape of the core. For example, in triangular strand constructions, triangular cores may be composed of triangular wires or of round wires laid in triangles. Only a wire rope made of round strands was analyzed inthis report. The other major structural element is the core around which the strands are

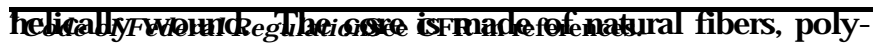
propylene,or steel that provide proper support for the strands under bending and loading in normal use. The most commonlyused cores are fiber core, independent wire rope core (IWRC), and wire strand core (WSC).

Although the strand can be laid in any one of many specificgeometric arrangements and composed of any number of wires, the rope also can have any number of strands. Therefore,wire rope generally is identified by the number of strands, the nominal or exact numberwires in each strand, 
and its specific geometric arrangement. When wires are laid in the direction opposite to that of the strands, the rope is called a regular lay rope. When wires are laid in the same direction as 
that of the strands, the rope is called a lang lay rope. If the strandsare laid into the rope to the right in a fashion similar to the threading in a right-hand bolt, they are right lay rope strands. Conversely, strands laid into the rope to the left are left lay rope strands. Different combinations of these wire ropelays are shown in figure 2. The WireRope Users Manual [Wire Rope Technical Board 1993] contains more detailed informationn wire rope identification and construction. Most of the rope produced today is preformed; this means that the wiresare permanently shaped into the helical form they will assumein the rope. This manufacturing process eliminates the tendencyof the wires to unlay, usually hazardously, when they are unrestrained or when the rope is cut.

\section{CLASSIFICATION OF WIRES}

It is assumed in this study that all wires have a circular crosssection and remain circular when they are stretched or bent. The centroidal axis, which lies along the center of a wire, is selected to represent the path of the wire and used to study its geometric characteristics that are related to wire stress. The centroidakis of the central wire of a strand also represents the path of the strand.

Based on the structural elements in a wire rope as describedabove, there is at most one straight wire in a straight rope. It is located in the center of a WSC or IWRC rope. The remaining wires can be classified geometrically into two groups: single helices or double helices. The outer wires in a straightstrand used as the WSC have a single helical form because they are helically wound only once around a straight axis. When a strand is helically wound into a rope, the central wirealso has a single helical form. All of the other wires have a double helical form because they are wound twice, once around the strand axis and another around the rope axis. Howeverthey remain single helices relative to the central wire of the strand in which they are wound. This relationship is important in the modeling of a double helical wire.

\section{STRUCTURAL PARAMETERS}

The following basic parameters specifying the helical structure are defined; the symbols representing them in the mathematical model are shown in parentheses.

1. Strandhelix axis $(\mathrm{Z})$ : The axis of the rope around whichthe strands are helically wound to form a rope or around whichthe wires are helically wound to form the center strand of a rope. The positive direction of the axis is defined to be the direction that the helix advances.

2. Wirehelix axis (W): The centroidal axis of the helical wire around which other wires are helically wound to form a strand. It is also the centroidal axis of a helical strand. The positivedirection of the axis is defined to be the direction that the helix advances.

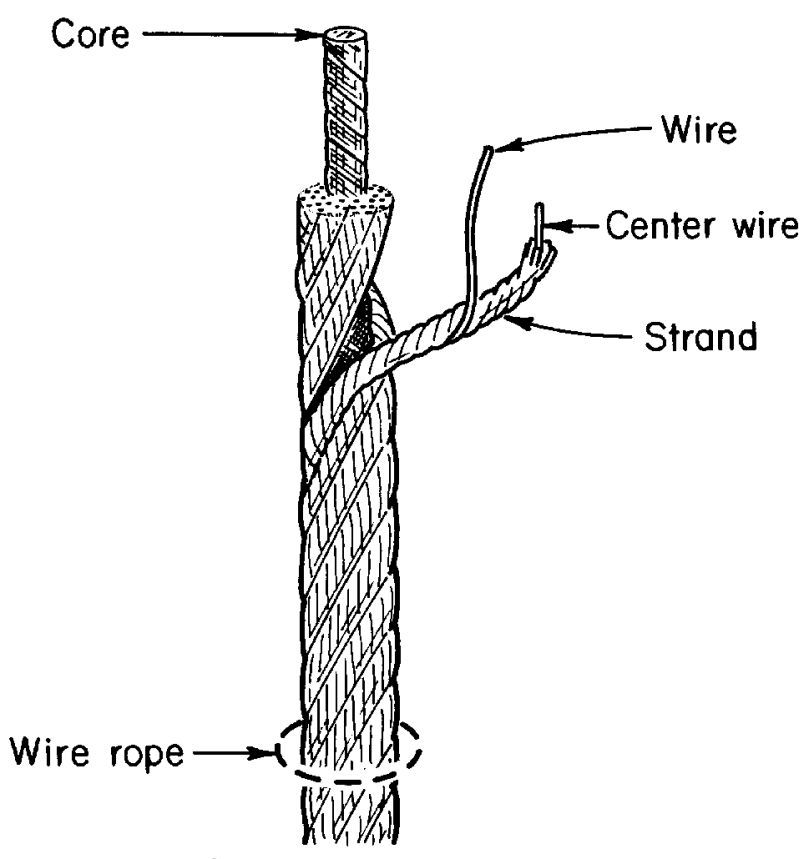

Figure 1.CStructural elements in a typical wire rope.

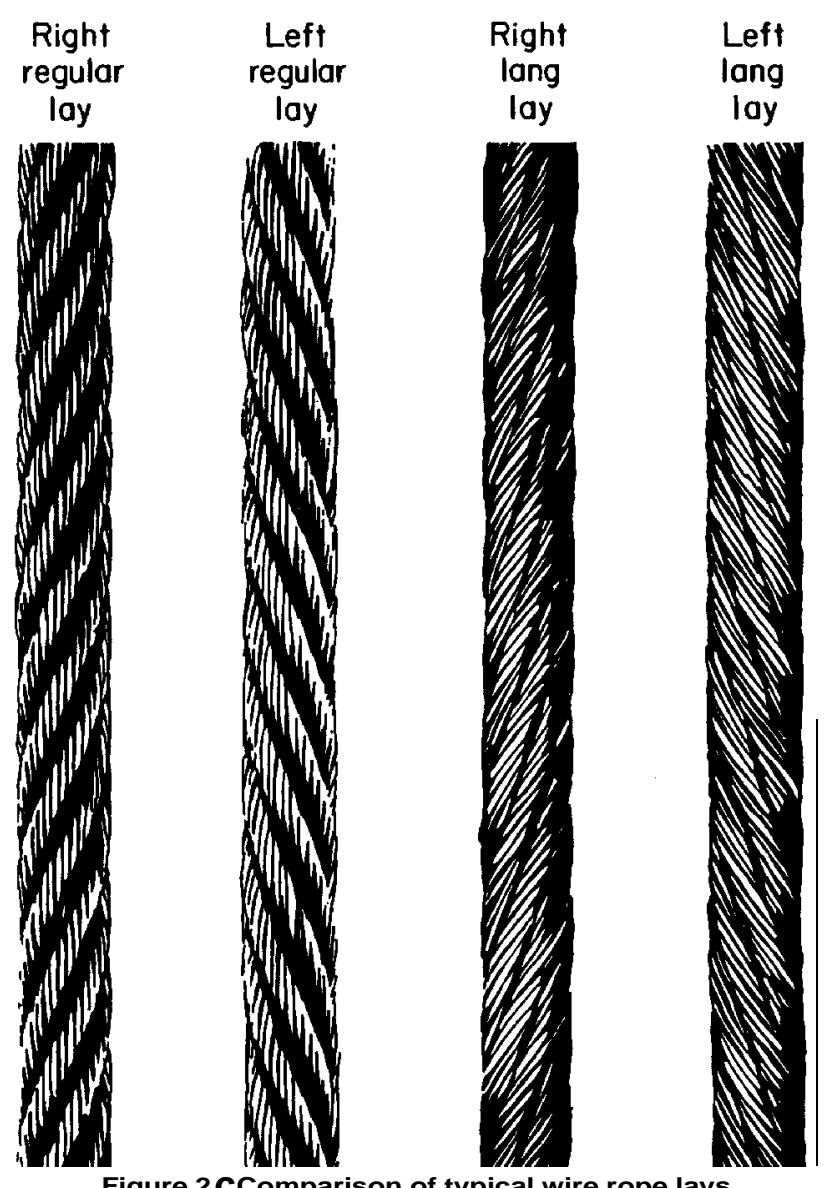

Figure 2.CComparison of typical wire rope lays. 
3. Radiusof strand helix $\left(\mathrm{r}_{\mathrm{s}}\right)$ : The perpendicular distance between the centroidal axis of the strand and the st helix axis.

4. Radius of wire helix $\left(\mathrm{r}_{\mathrm{w}}\right)$ : The perpendicular distancebetween the centroidal axis of the wire and the wire helix axis.

5. Circular helix The strand helix having a constant helical radius is a circular helix. Similarly, the wire helix having a constant helical radius is also a circular helix.

6. Angle of strand helix $\left(\alpha_{\mathrm{s}}\right)$ : The angle of a strand helix at any point along the centroidal axis of the strand is the angle between the tangent vector at that point, headirtigein directionthat the strand helix advances, and the plane that is perpendicular to thstrand helix axis and passes through that point.

7. Angle ofwire helix $\left(\alpha_{\mathrm{w}}\right)$ : The angle of a wire helix at any point along the centroidal axis of the wire is the angle between the tangent vector at that point, heading in the directionthat the wire helix advances, and the plane that is perpendicular to the wire helix axis and passes through that point.

8. Angleof strand rotation $\left(\theta_{\mathrm{s}}\right)$ : The angle at which the centroidalaxis of a helical strand sweeps out in a plane perpendiculato the strand helix axis. The angle is defined to be positivein a right-handed coordinate system if a right lay rope is formed and negative if a left lay rope is formed. The angle ranid expressed in radians, unless specified otherwise.

9. Angleof wire rotation $\left(\theta_{\mathrm{w}}\right)$ : The angle at which the centroidalaxis of a helical wire sweeps out in a plane perpendicular to the wire helix axis. The angle is defined to be positivein a right-handed coordinate system if a right-hand strand isformed and negative if a left-hand strand is formed. The angle is expresseid radians, unless specified otherwise.

10. Laylength of strand $\left(\mathrm{L}_{\mathrm{s}}\right)$ : The distance measured parallelto the axis of the rope around which the centroidal axis of a strand or wire makes one complete helical convolution.

11. Laylength (pitch) of wire $\left(\mathrm{L}_{\mathrm{w}}\right)$ : The distance measuredparallel to the wire helix axis around which the centroidal axis of a wire makes one complete helical convolution.

12. Lengthof rope $\left(\mathrm{S}_{\mathrm{r}}\right.$ or $\left.\mathrm{z}\right)$ : The length measured along the strand helix axis. It represents the distance that a strand helix has advanced on the axis of the rope.

13. Lengthof strand $\left(\mathrm{S}_{\mathrm{s}}\right.$ or $\left.\mathrm{w}\right)$ : The length measured alongthe wire helix axis. It represents the distance that a wire helix has advanced on the centroidal axis of the strand.

14. Lengthof wire $\left(\mathrm{S}_{\mathrm{w}}\right)$ : The path length measured along the centroidal axis of the wire.

\section{MATHEMATICAL MODELING}

\section{BASIC RELATIONSHIPS}

In circular helices, the centroidal axes of both the wire and the strand mabe considered to be lying on right circular cylinders. Because the surface of a cylinder can be developed into a plane, some basic relationships between each of the centroidalaxes and the other parameters can be established by using the developed views shown in figure 3 .

Therelationships between the length of rope and the angle of strand rotation and between the length of strand and the angle of strand rotation can be obtained by using the previouslydefined parameters and from the developed view of the strand helix and are expressed below.

$$
\begin{aligned}
& \mathrm{S}_{\mathrm{r}}=\mathrm{r}_{\mathrm{s}} \theta_{\mathrm{s}} \tan \left(\alpha_{\mathrm{s}}\right) \\
& \mathrm{S}_{\mathrm{s}}=\frac{\mathrm{r}_{\mathrm{s}} \theta_{\mathrm{s}}}{\cos \left(\alpha_{\mathrm{s}}\right)}
\end{aligned}
$$

Thelength of rope, $S_{r}$, in equation 1 becomes the lay length of strand, $\mathrm{L}_{\mathrm{s}}$, when $\theta_{\mathrm{s}}=2 \pi$. Similarly, the relationships between the length of strand and the angle of wire rotation and between the length of wire and the angle of wire rotation also can be obtainedby using the developed view of the wire helix and are expressed below.

$$
\begin{aligned}
& S_{s}=r_{w} \theta_{w} \tan \left(\alpha_{w}\right) \\
& S_{w}=\frac{r_{w} \theta_{w}}{\cos \left(\alpha_{w}\right)}
\end{aligned}
$$

The lengthof strand, $S_{s}$, in equation 3 becomes the lay length of wire, $L_{w}$, when $\theta_{w}=2 \pi$.

Becausethe length of strand obtained from the wire helix must equal that obtained from the strand helix for a given lengthof rope, a new term " $n$ " is defined to be the ratio of the angleof wire rotation to the angle of strand rotation, which can be obtained from equations 2 and 3 .

$$
\mathrm{n}=\frac{\theta_{\mathrm{w}}}{\theta_{\mathrm{s}}}=\frac{\mathrm{r}_{\mathrm{s}}}{r_{\mathrm{w}} \tan \left(\alpha_{\mathrm{w}}\right) \cos (}
$$

Thisratio is dependent on the angles of both helices when both helicalradii are fixed. It is considered to be important in characterizing the rope structure, specifically the relationship 

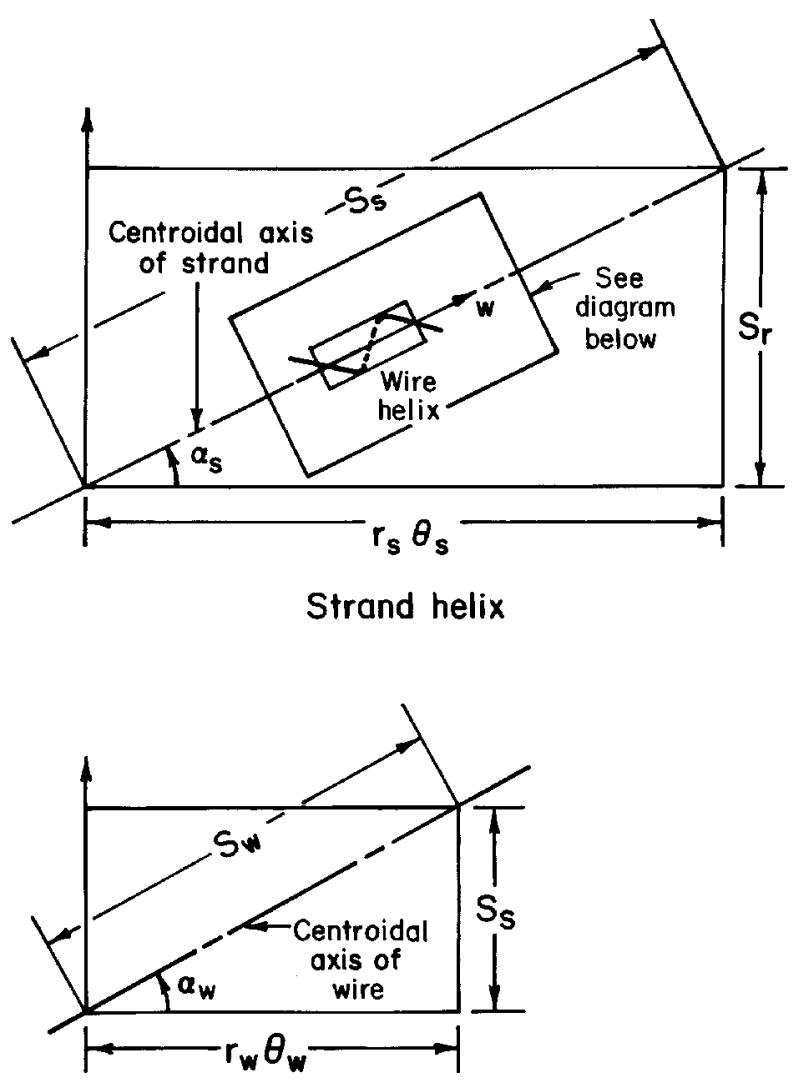

Wire helix

Figure 3.CDeveloped views of strand and wire helices.

betweenthe wire and strand helices, and is termed the "relative rotation"in this report. The relative rotation will be positive for lang lay ropes and negative for regular lay ropes.

\section{COORDINATE SYSTEMS}

Because severageometric characteristics of helices that are related to load distribution and wire stresses can be easily evaluatedhrough vector analysis, vector equations describing thesehelices are used to model the different wires in a rope. To distinguish vectors from scaldboldfacetypeis used for vectorsin the equations. Twothree-dimensional, right-handed, rectangularCartesian coordinate systems are selected to analyze the strand and wire helices.

Oneis a global fixed system called, for convenience, the ropecoordinate system (figure $4 A$ ). The coordinates are $\mathrm{X}, \mathrm{Y}$, and $\mathrm{Z}$ with the origiat the center of the rope and the $\mathrm{Z}$-axis coincidingwith the rope axis. The $\mathrm{X}-\mathrm{Y}$ plane is perpendicular to the rope axis and is the plane where the angle of strand rotationis measured. The $\mathrm{X}$-axis is arbitrarily selected so that it intersects, in its positive direction, with the centroidal axis of a strand. The $\mathrm{X}$-axis is also used as the reference line from whichthe angle of strand rotation, $\theta_{\mathrm{s}}$, is measured. The unit vectorsdirected along the positive directions of $\mathrm{X}, \mathrm{Y}$, and $\mathrm{Z}$ are $\mathbf{i}, \mathbf{j}$, andk, respectively.
The other, a local coordinate system, is the strand coordinate system (figure $4 B$ ). Its coordinates are $\mathrm{U}, \mathrm{V}$, and $\mathrm{W}$ with the origin on the centroidal axis of a strand. This local coordinate system moves along the centroidal axis of the strand. The $\mathrm{W}$-axis is in the direction of the tangent vector to the centroidal axis of the strand. The U-V plane is perpendicular to the centroidal axis of the strand and is the plane where the angle of wire rotation, $\theta_{w}$, is measured. The U-axis is parallel to the $\mathrm{X}-\mathrm{Y}$ plane and is also parallel to the line on the $\mathrm{X}-\mathrm{Y}$ plane that specifies the angle of strand rotation. The unit vectors directed along the positive directions of $\mathrm{U}, \mathrm{V}$, and $\mathrm{W}$ are $\mathbf{f}, \mathbf{g}$, and $\mathbf{h}$, respectively.

\section{VECTOR EQUATIONS FOR SINGLE AND DOUBLE HELICES}

The model describing the centroidal axis of the central wire of a strand in the rope using the rope coordinate system is a single helix model. The model describing the centroidal axis of a wire in a strand using the strand coordinate system is alsoa single helix model. Once these single helix models are formed,they will be used to develop a double helix model describinghe centroidal axis of a double helical wire in either a regular lay rope or a lang lay rope in the rope coordinate system.

\section{Single Helix Model}

When the rope coordinate system is placed at the center of the wire rope and a certain strand is specified to have an initial strand rotation angle of $\mathrm{O}$ at $\mathrm{z}=0$, as shown in figure $4 A$, the vector equation of the helix for the centroidal axis of this strand is

$$
\mathbf{R}=\mathrm{x}_{\mathrm{s}} \mathbf{i}+\mathrm{y}_{\mathrm{s}} \mathbf{j}+\mathrm{z}_{\mathrm{s}} \mathbf{k}
$$

Thesubscript "s" indicates variables that are associated with a singlehelix. The parametric equations of $\mathbf{R}$ for a circular strand helix are

$$
\begin{aligned}
& \mathrm{x}_{\mathrm{s}}=\mathrm{r}_{\mathrm{s}} \cos \left(\theta_{\mathrm{s}}\right), \\
& \mathrm{y}_{\mathrm{s}}=\mathrm{r}_{\mathrm{s}} \sin \left(\theta_{\mathrm{s}}\right),
\end{aligned}
$$

and

$$
\mathbf{z}_{\mathrm{s}}=\mathrm{r}_{\mathrm{s}} \theta_{\mathrm{s}} \tan \left(\alpha_{\mathrm{s}}\right)
$$

Thestrand rotation angle $\theta_{\mathrm{s}}$ in equations 7,8 , and 9 is positive for a right lay rope and negative for a left lay rope.

Similarly,when the strand coordinate system is initially placedon the centroidal axis of a certain strand at $\theta_{\mathrm{s}}=0$, a certain wire is specified to have an initial angle of wire rotation of $\mathrm{O}$ at $\mathrm{w}=0$, as shown in figure $4 B$. The vector equaion of the circular helix for the centroidal axis of this wireis similar to equation 6 in the rope coordinate system and can be written as 
$\mathbf{Q}=u \mathbf{f}+v \mathbf{g}+w \mathbf{h}$. 


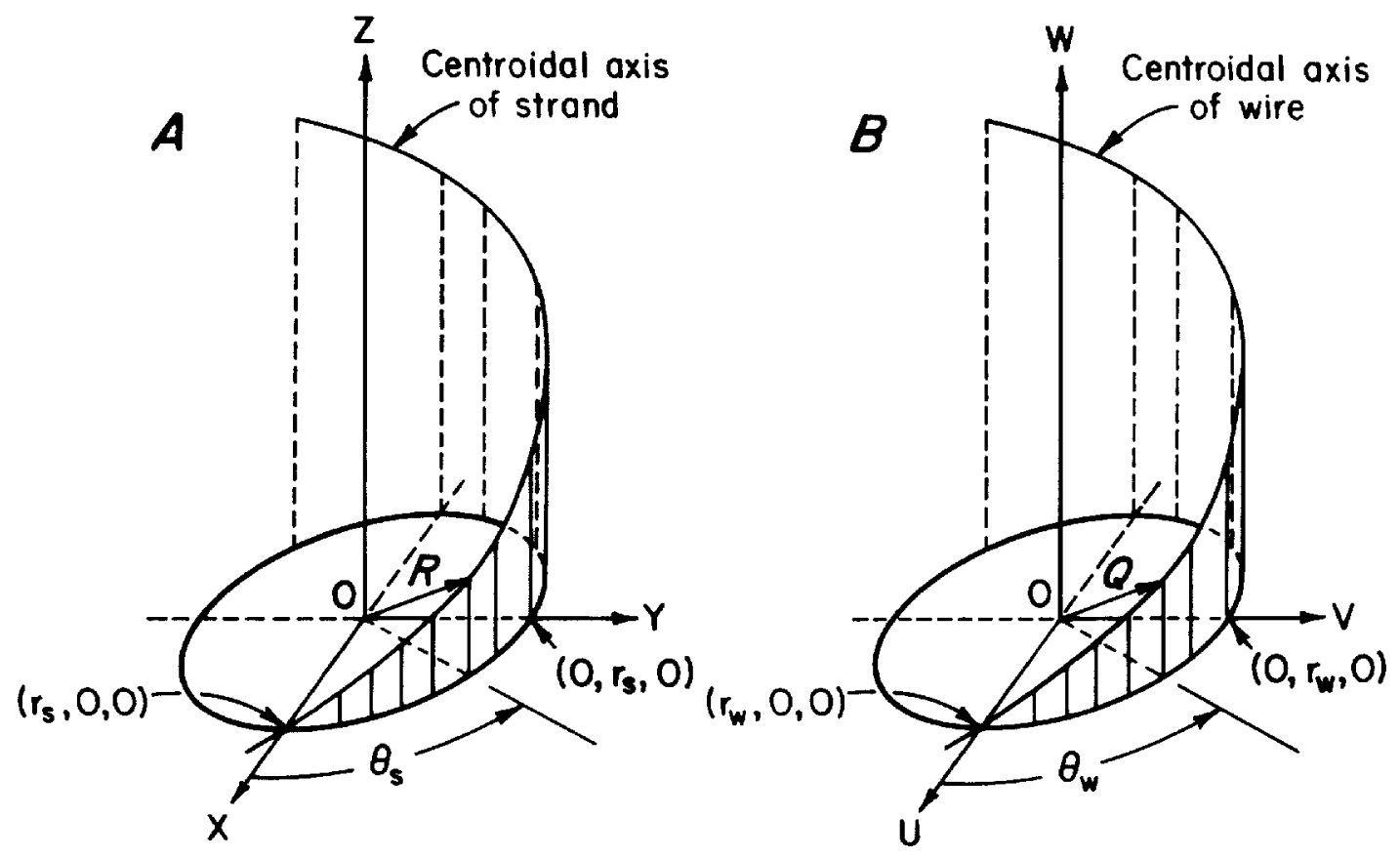

Figure 4.CCoordinate systems for single helix.A, rope coordinate system $B$, strand coordinate system.

The parametric equations of $\mathbf{Q}$ for a circular wire helix in a strand are

$$
\begin{aligned}
& \mathrm{u}=\mathrm{r}_{\mathrm{w}} \cos \left(\theta_{\mathrm{w}}\right), \\
& \mathrm{v}=\mathrm{r}_{\mathrm{w}} \sin \left(\theta_{\mathrm{w}}\right),
\end{aligned}
$$

and

$$
\mathbf{w}=\mathbf{r}_{\mathrm{w}} \theta_{\mathrm{w}} \tan \left(\alpha_{\mathrm{w}}\right)
$$

The wire rotation angle $\theta_{\mathrm{w}}$ in equations 11,12 , and 13 is positiveif it forms a right-hand strand and negative if it forms a left-handstrand. Because the coordinate system is moving alongthe centroidal axis of the strand, w simply represents the path length along the centroidal axis that the system has traveled for a wire rotation angle $\otimes_{\mathrm{f}}$.

\section{Double Helix Model}

The double helix model can be developed by properly combining the vector $\mathbf{R}$ in the rope coordinate system and a vectorq on the U-V plane dhe strand coordinate system, as shownin figure 5. It is assumed that, in the rope coordinate systema position vector $\mathbf{P}$ with the head of the vector located at $(\mathrm{u}, \mathrm{v}, \mathrm{w})$ of the strand coordinate system traces the centroidal axis of a double helical wire and has a general form

$$
\mathbf{P}=\mathrm{x}_{\mathrm{w}} \mathbf{i}+\mathrm{y}_{\mathrm{w}} \mathbf{j}+\mathrm{z}_{\mathrm{w}} \mathbf{k}
$$

wherex ${ }_{w}, y_{w}$, and $z_{w}$ are the component functions. The subscript "w" indicates variables that are associated a double helix.

The vector $\mathbf{q}$ in the strand coordinate system is a position vectorthat traces the centroidal axis of a double helical wire on the U-V plane at a certain value of $w$ in the strand coordinate system. The vector equation for $\mathbf{q}$ may be written as

$$
\mathbf{q}=\mathrm{u} \mathbf{f}+\mathrm{v} \mathbf{g}
$$

The w component is not needed in specifying the location of thecentroidal axis of a double helical wire because $\mathbf{q}$ is always on the U-V plane. The parametric equations for $\mathrm{u}$ and $\mathrm{v}$ are identical to equations 11 and 12 .

Becausethe head of $\mathbf{R}$ is located exactly at the tail of $\mathbf{q}$, the vector $\mathbf{P}$ can be readily obtained through vector addition once the vectoq in the strand coordinate system is projected to the rope coordinate system. Using the fact that the U-axis is parallel to the $\mathrm{X}-\mathrm{Y}$ plane and the line that specifies the angle of strand rotation $\left(\theta_{\mathrm{s}}\right)$ and that the $\mathrm{U}-\mathrm{V}$ plane is perpendicular to the $\mathrm{W}$-axis, which has an angle of strand helix $\left(\alpha_{\mathrm{s}}\right)$, the individualprojections of $u$ and $v$ on the $\mathrm{X}$-, $\mathrm{Y}$-, and $\mathrm{Z}$-axes are 


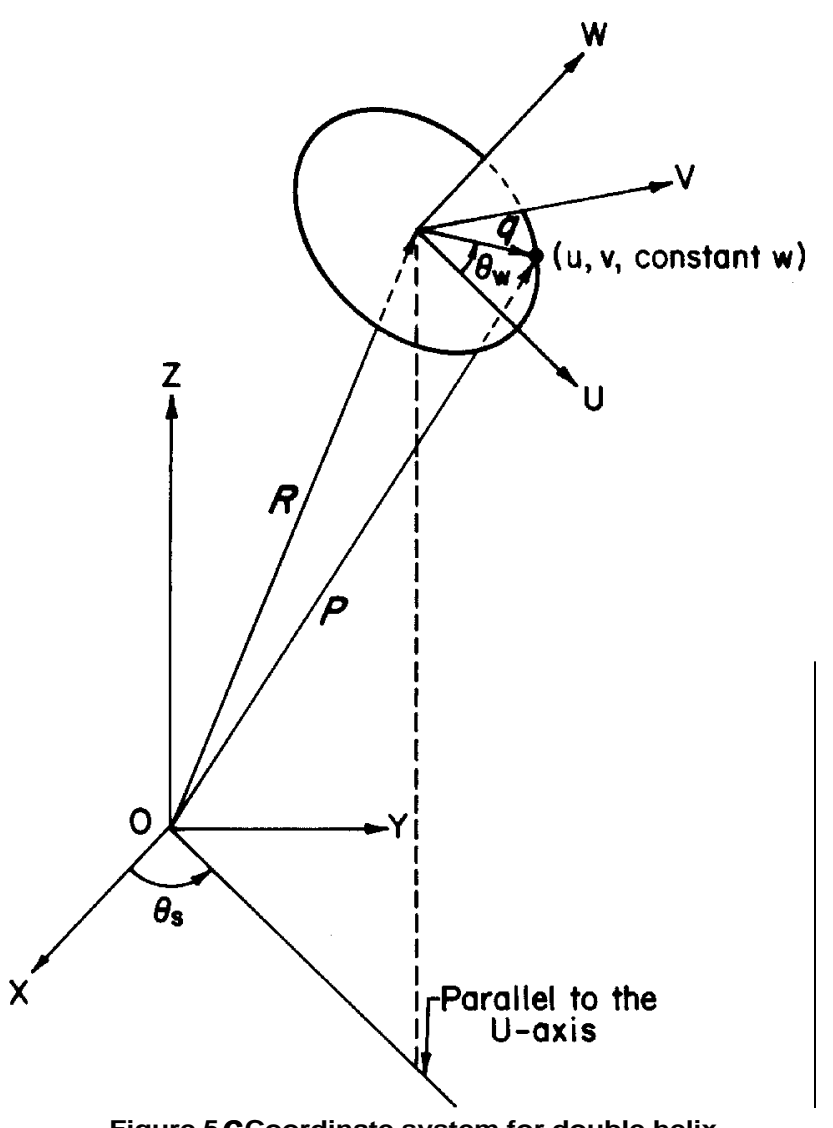

Figure 5.CCoordinate system for double helix.

$$
\begin{gathered}
\left.\mathrm{x}_{\mathrm{u}}=\mathrm{u} \cos \theta_{\mathrm{s}}\right), \\
\left.\mathrm{y}_{\mathrm{u}}=\mathrm{u} \sin \theta_{\mathrm{s}}\right), \\
\mathrm{z}_{\mathrm{u}}=0, \\
\mathrm{x}_{\mathrm{v}}=-\mathrm{v} \sin \left(\alpha_{\mathrm{s}}\right) \sin \left(\theta_{\mathrm{s}}\right), \\
\mathrm{y}_{\mathrm{v}}=\mathrm{v} \sin \left(\alpha_{\mathrm{s}}\right) \cos \left(\theta_{\mathrm{s}}\right),
\end{gathered}
$$

and

$$
\mathrm{z}_{\mathrm{v}}=-\mathrm{v} \cos \left(\alpha_{\mathrm{s}}\right) \text {. }
$$

The vector $\mathbf{q}$ now can be expressed in the rope coordinate system as

$$
\mathbf{q}=\left(\mathrm{x}_{\mathrm{u}}+\mathrm{x}_{\mathrm{v}}\right) \mathbf{i}+\left(\mathrm{y}_{\mathrm{u}}+\mathrm{y}_{\mathrm{v}}\right) \mathbf{j}+\left(\mathrm{z}_{\mathrm{u}}+\mathrm{z}_{\mathrm{v}}\right) \mathbf{k} \text {. }
$$

Because the vector is the sum or andq, the general form of the vector equation fdr now can be written as

$\mathbf{P}=\left(\mathrm{x}_{\mathrm{s}}+\mathrm{x}_{\mathrm{u}}+\mathrm{x}_{\mathrm{v}}\right) \mathbf{i}+\left(\mathrm{y}_{\mathrm{s}}+\mathrm{y}_{\mathrm{u}}+\mathrm{y}_{\mathrm{v}}\right) \mathbf{j}+\left(\mathrm{z}_{\mathrm{s}}+\mathrm{z}_{\mathrm{u}}+\mathrm{z}_{\mathrm{v}}\right) \mathbf{k} .(23)$
By introducing the relative rotationdefined by equation 5) into equations $7,8,9,16,17,19$, and 20 , replacing $u$ and $v$ withequations 11 and 12, and substituting them into equation 23 , the following component functions for the double helix model in terms of only wire rotation angle are obtained.

$$
\begin{aligned}
= & r_{s} \cos \left(\frac{\theta_{w}}{n}\right)+r_{w} \cos \left(\theta_{w}\right) \cos ( \\
& -r_{w} \sin \left(\alpha_{s}\right) \sin \left(\theta_{w}\right) \sin \left(\frac{\theta_{w}}{n}\right.
\end{aligned}
$$

The sign for $\theta_{\mathrm{w}}$ is positive when it rotates counterclockwise

$$
\begin{aligned}
\mathrm{y}_{\mathrm{w}}= & \mathrm{r}_{\mathrm{s}} \sin \left(\frac{\theta_{\mathrm{w}}}{\mathrm{n}}\right)+\mathrm{r}_{\mathrm{w}} \cos \left(\theta_{\mathrm{w}}\right) \sin \left(\frac{\theta_{\mathrm{w}}}{\mathrm{n}}\right. \\
& +\mathrm{r}_{\mathrm{w}} \sin \left(\alpha_{\mathrm{s}}\right) \sin \left(\theta_{\mathrm{w}}\right) \cos \left(\frac{\theta_{\mathrm{w}}}{\mathrm{n}}\right) \\
& \mathrm{z}_{\mathrm{w}}=\mathrm{r}_{\mathrm{s}} \tan \left(\alpha_{\mathrm{s}}\right) \frac{\theta_{\mathrm{w}}}{\mathrm{n}}-\mathrm{r}_{\mathrm{w}} \cos \left(\alpha_{\mathrm{s}}\right) \sin \left(\theta_{\mathrm{w}}\right)
\end{aligned}
$$

and negative when it rotates clockwise. The lay type determinesthe sign for $\mathrm{n}$ as defined by equation 5 . The component $\mathrm{z}_{\mathrm{w}}$ is always positive and increases in the direction that the helix advances.

\section{EXAMPLE FOR A SPECIFIC WIRE ROPE}

The circular helix models presented above are applicable to any type of rope construction as long as its strands are round, i.e., the wires are laid in circular pattern. As an example,the structural parameters of a 33-mm $6 \times 19$ Seale, IWRC,right regular lay wire rope are used to show how the model for a specific rope is obtained.

Thebasic strand arrangement of a $6 \times 19$ Seale wire rope is shown in figure 6 . The structural parameters of different strandsare presented in table 1 . The strand cross sections perpendicularto the strand or wire helix axis are shown in figures 7 through 9. The structural parameters of the single anddouble helical wires in each strand are presented in table 2. Some of the parameters, such as the lay length of strand, the lay length of wire, and the relative rotation, were calculated basedon the basic relationships given by equations 1,3 , and 5 .

The model for single helical wires can be obtained by simply substituting the values of pherameters $r_{s}$ and $\alpha_{s}$, as indicatedin table 2 , into equations 7,8 , and 9 . The model for doublehelical wires can be obtained by substituting the values of the parameters $r_{s}, r_{w}, \alpha_{s}$, and $n$ as shown in table 2 into equations 24, 25, and 26. As examples, the component functions of the model for each type of wire in the rope are presented below. 


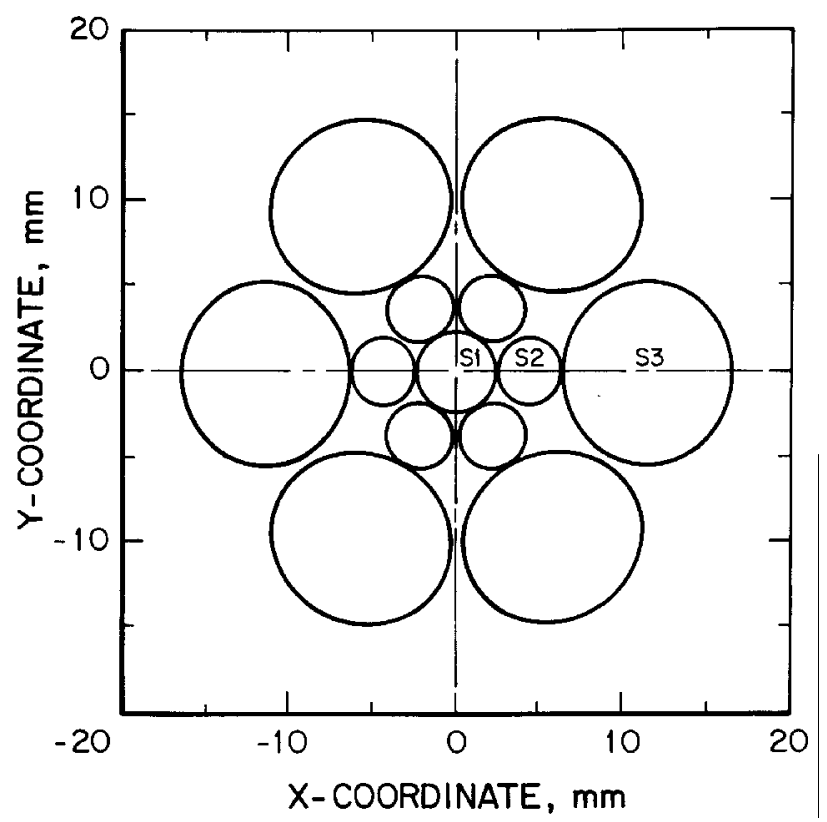

Figure6.CStrand arrangement of 33-mm 6×19 Seale, IWRC, right regular lay wire rope.

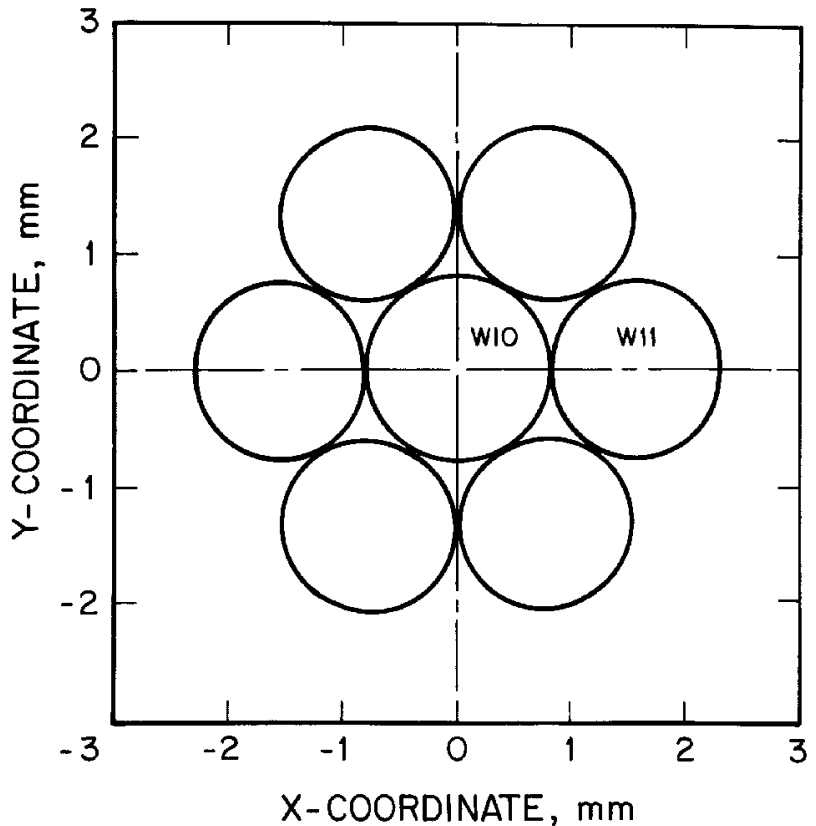

Figure 7.CCross section of IWRC strand S1.

Table 1.CStructural parameters of strands in 33- $\mathrm{mm} 6 \times 19$ Seale wire rope

\begin{tabular}{|c|c|c|c|c|c|c|}
\hline \multirow[b]{2}{*}{ Strand } & \multirow[b]{2}{*}{ Form } & \multirow{2}{*}{$\begin{array}{l}\text { No. of } \\
\text { strands }\end{array}$} & \multirow{2}{*}{$\begin{array}{c}\text { Strand } \\
\text { radius, } \\
\mathrm{mm}\end{array}$} & \multicolumn{3}{|c|}{ Helix parameters } \\
\hline & & & & $\begin{array}{c}\mathrm{r}_{\mathrm{s}}, \\
\mathrm{mm}\end{array}$ & $\begin{array}{c}\alpha_{\mathrm{s}} \\
\mathrm{rad}\end{array}$ & $\begin{array}{l}\mathrm{L}_{\mathrm{s}}, \\
\mathrm{mm}\end{array}$ \\
\hline \multicolumn{7}{|l|}{ IWRC: } \\
\hline S1. & Straight . & 1 & 2.271 & NAp & NAp & NAp \\
\hline S2. . & Single helix. & 6 & 2.016 & 4.287 & 1.2362 & 77.48 \\
\hline Seale: & & & & 11.41 & & \\
\hline s3........ & Single helix. & 6 & 5.110 & 3 & 1.2259 & 199.61 \\
\hline
\end{tabular}

Table 2.CStructural parameters of wires in 33- $\mathrm{mm} 6 \times 19$ Seale wire rope

\begin{tabular}{|c|c|c|c|c|c|c|c|c|c|}
\hline \multirow[b]{2}{*}{ Wire } & \multirow{2}{*}{$\begin{array}{l}\text { No. of } \\
\text { wires per } \\
\text { strand }\end{array}$} & \multirow{2}{*}{$\begin{array}{l}\text { Wire } \\
\text { radius, } \\
\mathrm{mm}\end{array}$} & \multicolumn{7}{|c|}{ Helix parameters } \\
\hline & & & $\begin{array}{l}\mathrm{r}, \\
\mathrm{mm}\end{array}$ & $\begin{array}{l}\alpha_{\mathrm{s}}, \\
\mathrm{rad}\end{array}$ & $\begin{array}{c}\mathrm{L}_{\mathrm{s}}, \\
\mathrm{mm}\end{array}$ & $\begin{array}{c}\mathrm{r}_{\mathrm{w}}, \\
\mathrm{mm}\end{array}$ & $\begin{array}{l}\alpha_{w}, \\
\text { rad }\end{array}$ & $\begin{array}{l}\mathrm{L}_{\mathrm{w}}, \\
\mathrm{mm}\end{array}$ & $\mathrm{n}$ \\
\hline \multicolumn{10}{|l|}{ Straight: } \\
\hline W10... & 1 & 0.801 & NAp & NAp & NAp & NAp & NAp & NAp & NAp \\
\hline \multicolumn{10}{|l|}{ Single helical: } \\
\hline W11 $\ldots \ldots \ldots$ & 6 & 0.735 & 1.536 & 1.2864 & 33.02 & NAp & NAp & NAp & NAp \\
\hline W20. & 1 & 0.704 & 4.287 & 1.2362 & 77.48 & NAp & NAp & NAp & NAp \\
\hline W30. & 1 & 1.456 & 11.413 & 1.2259 & 199.61 & NAp & NAp & NAp & NAp \\
\hline \multicolumn{10}{|l|}{ Double helical: } \\
\hline W21. & 6 & 0.656 & 4.287 & 1.2362 & 77.48 & 1.360 & 1.4149 & 54.37 & 1.5087 \\
\hline W31. & 9 & 0.712 & 11.413 & 1.2259 & 199.61 & 2.168 & 1.7849 & 62.65 & -3.3855 \\
\hline W32. & 9 & 1.243 & 11.413 & 1.2259 & 199.61 & 3.867 & 1.9408 & 62.65 & -3.3855 \\
\hline
\end{tabular}




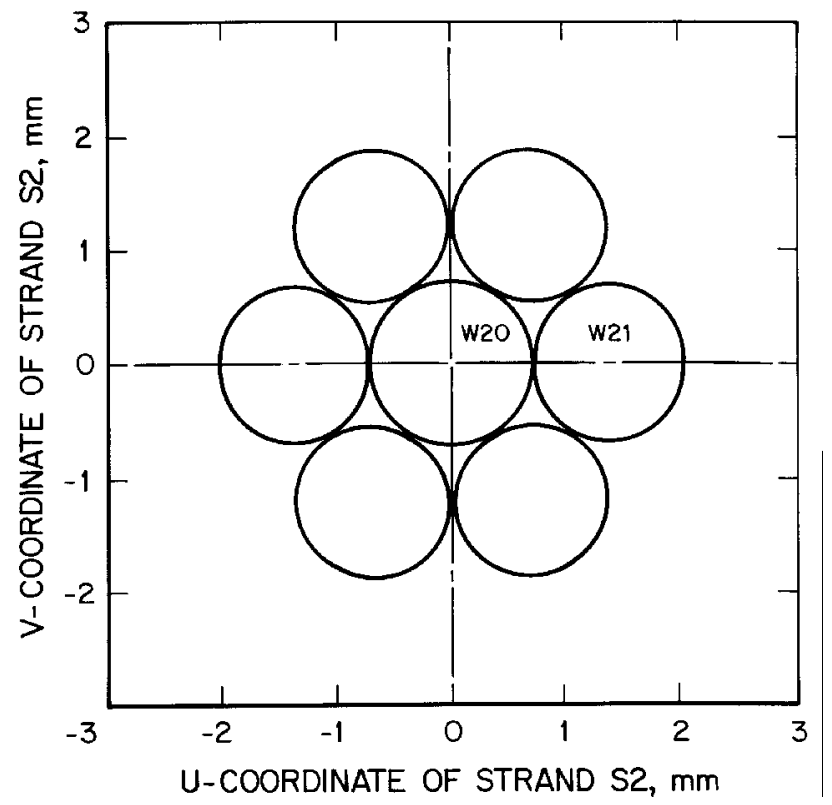

Figure 8.CCross section of IWRC strand S2.

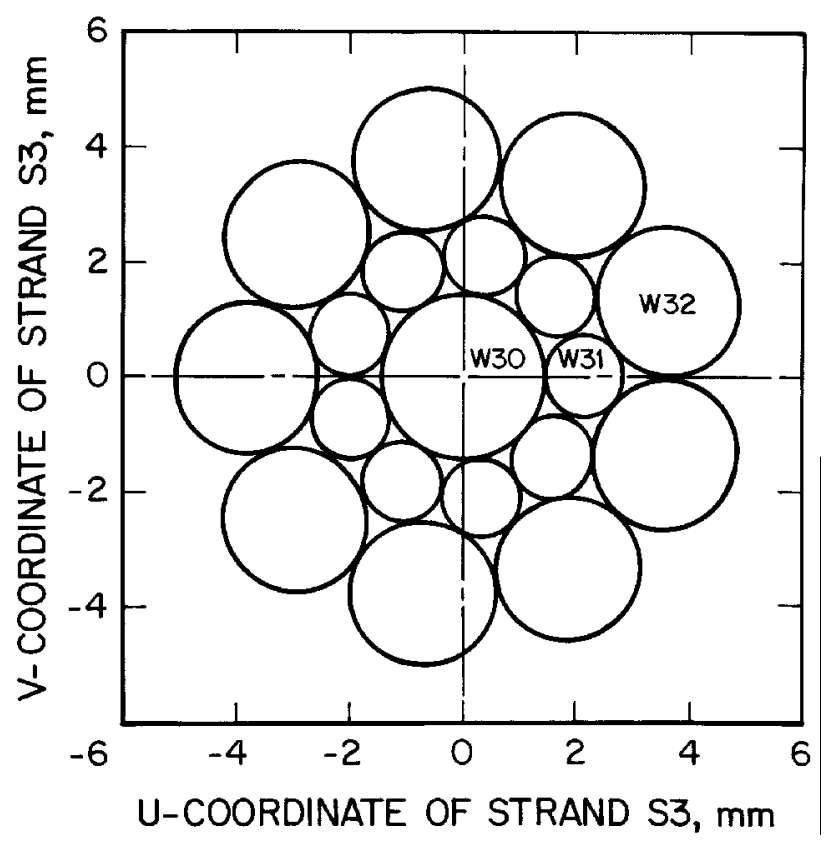

Figure 9.CCross section of Seale strand S3.

1. Wire $W 10$

Because this is the center wire of the rope, its path is always on the Z-axis. The vector equation has only one component in the direction of $\mathbf{k}$, and the magnitude is simply the rope length.
2. Wire W11

$$
\begin{gathered}
\left.\mathrm{x}_{\mathrm{s}}=1.536 \cos \theta_{\mathrm{s}}\right) \\
\left.\mathrm{y}_{\mathrm{s}}=1.536 \sin \theta_{\mathrm{s}}\right) \\
\mathrm{z}_{\mathrm{s}}=5.255 \theta_{\mathrm{s}}
\end{gathered}
$$

3. Wire 20

$$
\begin{gathered}
\mathrm{x}_{\mathrm{s}}=4.287 \cos \left(\theta_{\mathrm{s}}\right) \\
\mathrm{y}_{\mathrm{s}}=4.287 \sin \left(\theta_{\mathrm{s}}\right) \\
\mathrm{z}_{\mathrm{s}}=12.331 \theta_{\mathrm{s}}
\end{gathered}
$$

4. Wire W21

$$
\begin{aligned}
x_{w}= & 4287 \cos \left(\frac{\epsilon}{1 \cdot 5}\right. \\
& +1.360 \cos \left(\theta_{w}\right) \\
& -1.285 \sin \left(\theta_{w}\right) \\
y_{w}= & .287 \sin \left(\frac{\epsilon}{1 \cdot 5}\right. \\
& +1.360 \cos \left(\theta_{w}\right) \\
& +1.285 \sin \left(\theta_{w}\right) \\
& \left.z_{w}=8.173 \theta_{w}-0.447 \sin \theta_{w}\right)
\end{aligned}
$$

5. Wire $W 30$

$$
\begin{aligned}
& \mathrm{x}_{\mathrm{s}}=11.413 \cos \left(_{\mathrm{s}}\right) \\
& \mathrm{y}_{\mathrm{s}}=11.413 \sin \left(\theta_{\mathrm{s}}\right)
\end{aligned}
$$


6. Wire W31

$$
\begin{aligned}
x_{w}= & 11.413 \cos \left(\frac{\theta_{w}}{-3 \cdot 3 \varepsilon}\right. \\
& +2.168 \cos \left(\theta_{w}\right) \cos \\
& -2.040 \sin \left(\theta_{w}\right) \sin \\
y_{w}= & 1.413 \sin (= \\
& +2.168 \cos (1 \\
& +2.040 \sin (
\end{aligned}
$$

7. Wire W32

$$
\begin{aligned}
x_{w}= & 11.413 \cos \left(\overline{\frac{-3}{-3}}\right. \\
& +3.867 \cos \left(\theta_{w}\right) \\
& -3.639 \sin \left(\theta_{w}\right) \\
y_{w}= & 1.413 \sin \left(\frac{z_{w}}{\overline{-3} \cdot 38} \theta_{w}\right. \\
& \left.+3.864 \theta_{w}-1.307 \sin \theta_{w}\right) \\
& +3.639 \cos \left(\theta_{w}\right) \sin \left(\theta_{w}\right) \cos
\end{aligned}
$$

\section{MODEL APPLICATIONS}

Themodel for a specific wire rope can be easily obtained, as shown in the example above, and has many practical applications. It can be used to generate the wire paths and to evaluatethe geometric properties of the wires. The effect of deformation can be determined by substituting the structural parametersof the deformed rope into the original model. The model also has other applications, such as predicting damage patternsthrough external and internal wear, examining and improvingthe design of a rope construction prior to manufacturing, and producing three-dimensional pictures of the wires for computer analysis.

\section{GENERATION OF WIRE PATHS}

As described earlier, the wires in wire ropes have three forms: straight, single helix, or double helix. The only straightwire in a rope is the center wire in an IWRC. The wiresaround the center wire forming the center strand and the centerwires in the outer strands of the core and in the surface strandshave the shape of a single helix. The wires forming the $\begin{array}{lllllllllllllllll} & \mathrm{u} & \mathrm{t} & \mathrm{e} & \mathrm{r} & \mathrm{s} & \mathrm{t} & \mathrm{r} & \mathrm{a} & \mathrm{n} & \mathrm{d} & \mathrm{s}\end{array}$ of the core and the surface strands except their center wires have double helical paths that are very complex in their
configurations.Using the model developed in this report, the wirepaths can be easily generated by a computer. They not only reveal the shapesf the wire paths, but also are useful in locatingthe places where a wire will be rubbed by the other wiresand in determining the interval at which an outer wire will be exposed on the rope surface.

age Typicalpaths of single helical wires generated by equations 7a-8a-9a, 7b-8b-9b, and 7c-8c-9c for wires W11, W20 and W30, respectively, are shown in figure 10. The paths shownare in about one lay of strand S3. Typical paths of doublehelical wires generated by equations 24a-25a-26a, 24b25b-26band 24c-25c-26c for wires W21, W31, and W32, respectively, are shown in figures 11 through 13 . The paths shownare in about two lays of the strand formed by each wire. The reason for the majolifference between the shape of the W21 path and that of the W31 and W32 paths is that strand S2, whichcontains wire W21, is a lang lay strand, whereas strand $\mathrm{S} 3$, which contains $\mathrm{W} 31$ and $\mathrm{W} 32$, is a regular lay strand. The side views ofll wire paths show much sharper turns than the actual wire paths. This is because much larger scales have been selected on the $\mathrm{Y}$ coordinate than those on the $\mathrm{Z}$ coordinate of these figures so that more of their paths can be viewed. 


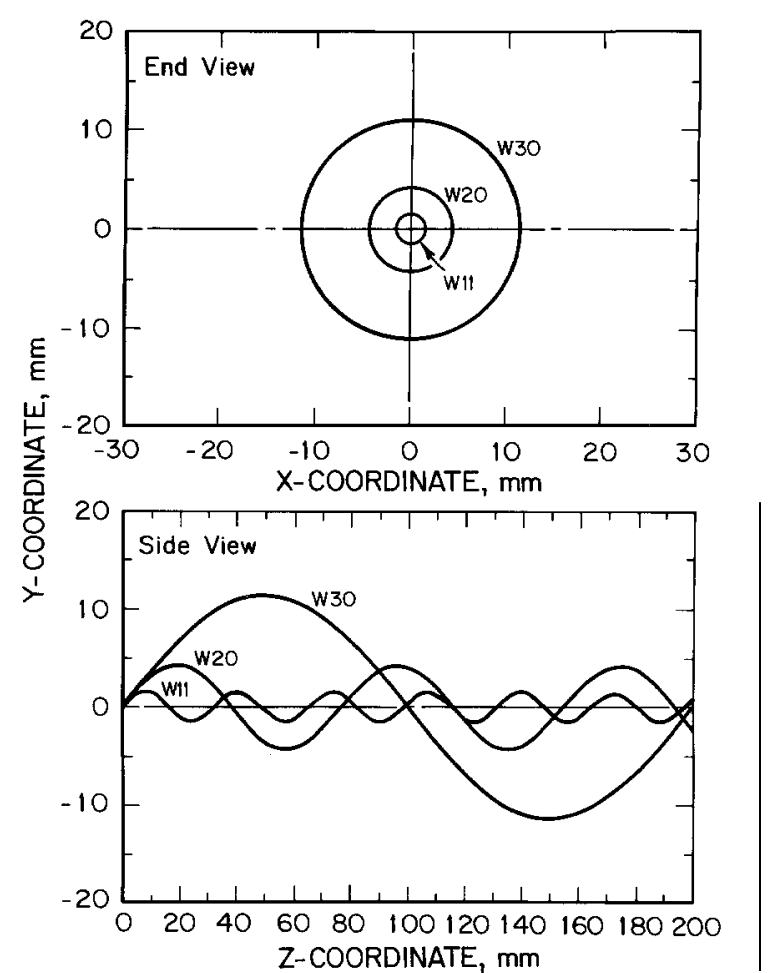

Figure 1đCPaths of single helical wires W11, W20, W30.

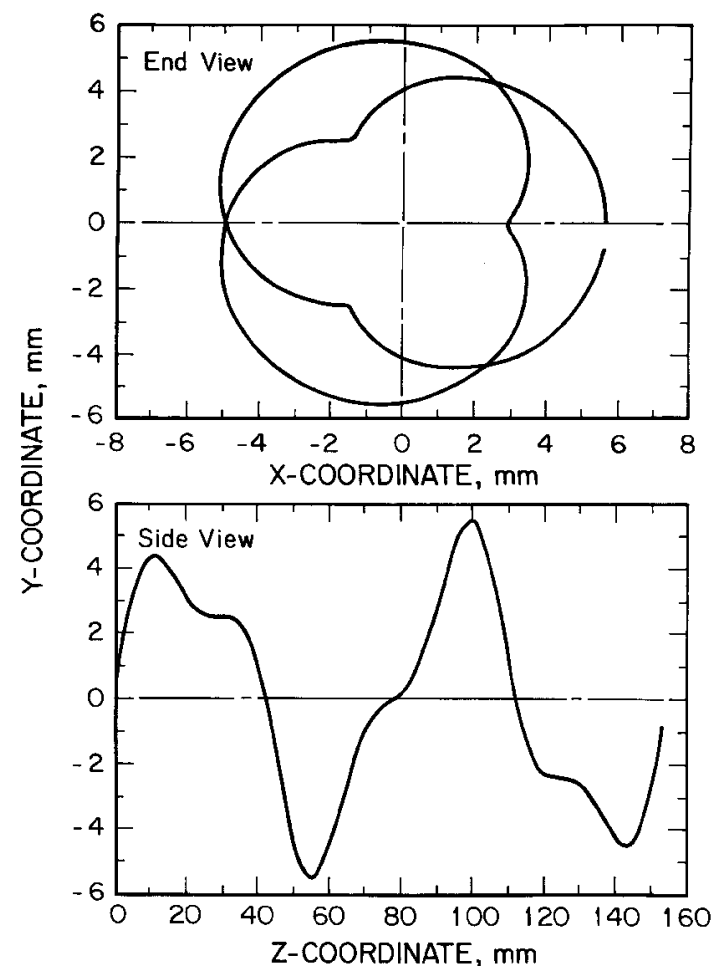

Figure 11CPath of double helical wire W21.
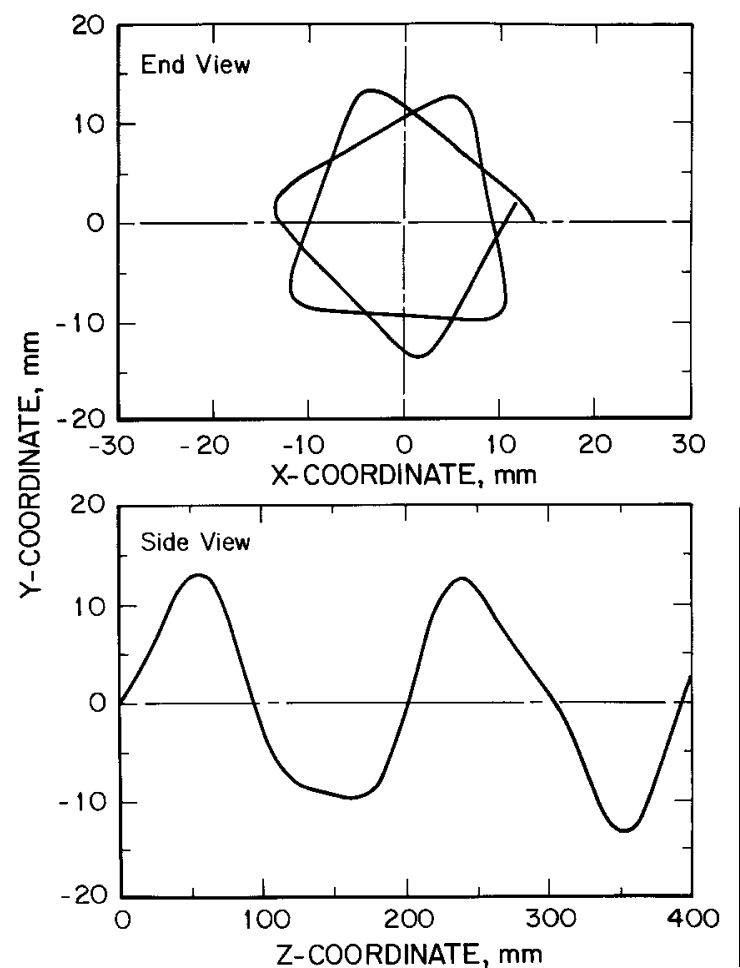

Figure 12.Path of double helical wire W31.

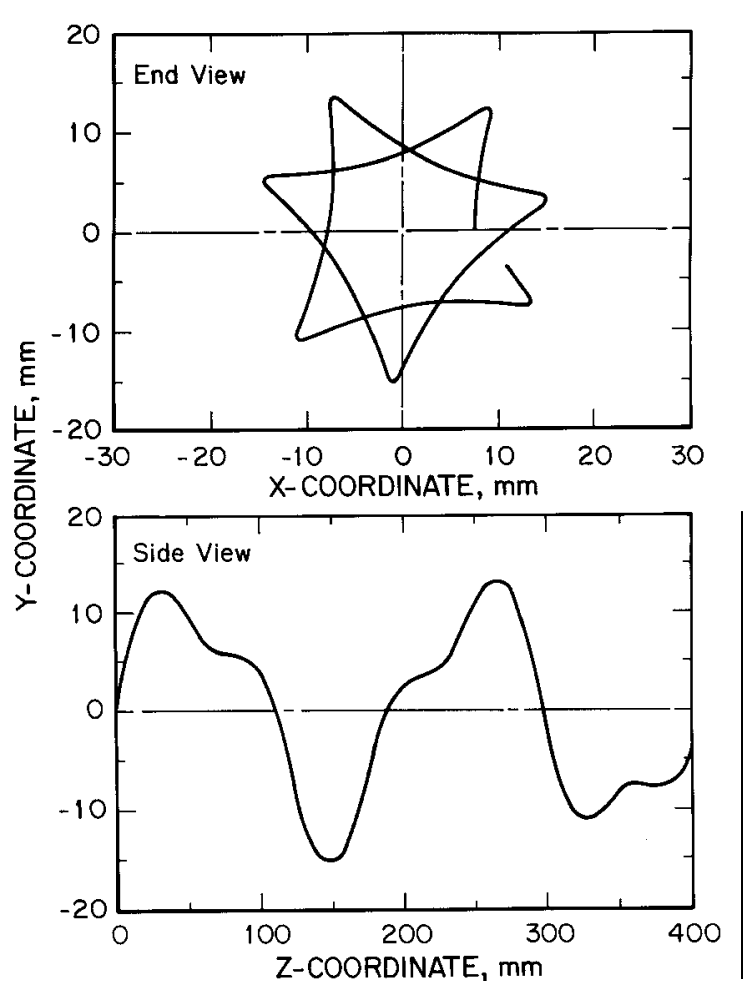

Figure 13.Path of double helical wire W32. 
EVALUATION OF GEOMETRIC PROPERTIES

To learn how the tensile load is distributed among the wires in a rope and to calculate wire stresses, several geometric properties of each wire must be evaluated before and after the application of load. These properties are the path length, curvature, and torsion.

\section{Path Length Per Lay of Strand}

The equations for evaluation of the path length of single and double helical wires in each lay of the strand can be derived from equations 2, 3, and 4 and are shown in equations 27 and 28.

Path length of single helical wires in each lay of strand:

$$
\mathrm{S}_{\mathrm{s}}=\frac{2 \pi \mathrm{r}_{\mathrm{s}}}{\cos \left(\alpha_{\mathrm{s}}\right)}
$$

Path length of double helical wires in each lay of strand:

$$
\mathrm{S}_{\mathrm{w}}=\frac{2 \pi \mathrm{r}_{\mathrm{s}}}{\cos \left(\alpha_{s}\right) \sin \left(\alpha_{w}\right)}
$$

Table 3 shows the path lengths per lay of strand for a $6 \times 19$ Seale rope as calculated by equations 27 and 28. The table also shows the wire-to-rope length ratios by comparing the wire paths to the strand lay lengths.

\begin{tabular}{|c|c|c|c|c|}
\hline Wre & $\begin{array}{l}\text { Lay length } \\
\text { of strand } \\
\text { referred to }\end{array}$ & $\begin{array}{l}\text { Lay length } \\
\text { of strand } L_{s}, \\
\text { mm }\end{array}$ & $\begin{array}{l}\text { Path length } \\
\text { per lay } \\
\text { of strand, } \\
\text { mm }\end{array}$ & $\begin{array}{l}\text { Wre-to-rope } \\
\text { length } \\
\text { ratio }\end{array}$ \\
\hline \multicolumn{5}{|l|}{ Straight: } \\
\hline W10. & NAp & NAp & NAp & 1.000 \\
\hline \multicolumn{5}{|l|}{ Single helical: } \\
\hline W11 & $\mathrm{L}_{11}$ & 33.02 & 34.40 & 1.042 \\
\hline W2O & $L_{20}$ & 77.48 & 82.03 & 1.059 \\
\hline W30 & $\mathrm{L}_{30}^{\infty}$ & 199.61 & 212.10 & 1.063 \\
\hline \multicolumn{5}{|l|}{ Double helical: } \\
\hline W21 & $\mathrm{L}_{20}$ & 77.48 & 83.04 & 1.072 \\
\hline W31 & $L_{30}$ & 199.61 & 217.06 & 1.087 \\
\hline W32 & $L_{30}$ & 199.61 & 227.50 & 1.140 \\
\hline
\end{tabular}

Table 3.CPath length of wires per lay of strand

NAp Notapplicable.

\section{Curvature and Torsion}

A special moving frame of reference, similar to the strand coordinate systemadapted in the mathematical modeling, has been used in the generation of the basic equations for evaluation of the curvature and torsion of a curve in three-dimensional space [Sokolnikoff and Redheffer 1958; Leithold 1986]. This frame is formed by a three-dimensional, right-handed set of orthogonal unit vectors, as shown in figure 14 . The origin of the frame is located at the head of any position vector that may be Ror Pof the models just developed. The three unit vectors $\mathbf{t}, \mathbf{n}$, and $\mathbf{b}$ are called the unit tangent, the unit principal normal, and the unit binormal vectors, respectively. The frame is sometimes referred to as the "moving trihedral" associated with the curve.

The curvature at a certain point of a curve is a measure of how quickly the curve changes direction at that point. It is the reciprocal of the radius of the curve at that point and expressed in the unit of $1 / \mathrm{mm}$ in this report. In a wire, a change of the curvature is produced by bending moments that act on the wire cross section. Curvature not only is related to the shearing stress, but also affects the distribution of the tensile stress on the cross section. Therefore, the deformation of the rope structure in terms of the curvature change needs to be specified to determine its effect on shearing and normal stresses.

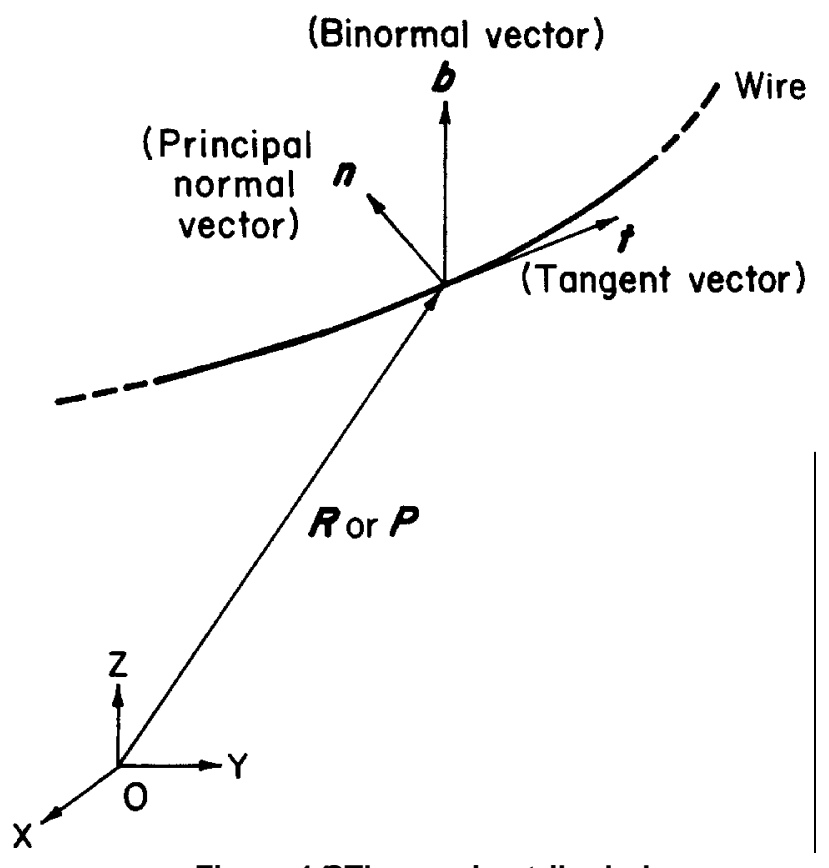

Figure 14. The moving trihedral. 
The curvature vector is defined to be the first derivative of $\mathbf{t}$ in the moving trihedral, as shown in figure 14, with respect to arc length of a curve. It can be expressed as $\kappa \mathbf{n}$, where $\kappa$ is a scalar multiplier. The curvature vector is in the same direction of the principal normal vector. The magnitude of this vector is called the curvature of the curve and is simply equal to $\kappa$ because the magnitude of $\mathbf{n}$ is unity. The curvature of a straight line is always zero because the tangent vector is constant. The curvature of the centroidal axis of either a single or a double helical wire, therefore, may be specifically defined to be the magnitude of the rate of change of the unit tangent vector with respect to arc length of the wire.

Basic formulas derived for evaluation of curvature are expressed in terms of the position vector with arc length as the parameter, because arc length arises naturally from the shape of the curve [Sokolnikoff and Redheffer 1958]. To directly apply the model developed in this report, it is more convenient to use equations 29 and 30 for computation of the curvature [Stewart 1991]. The vectors $\mathbf{R}$ and $\mathbf{P}$ denoted with single and double primes in the equations represent the first and second derivatives, respectively, with regard to $\theta_{\mathrm{s}}$ or $\theta_{\mathrm{w}}$ just as for real-valued functions. Similarly, the vectors denoted with triple primes, to be used later in this report, represent the third derivatives with respect to $\theta_{\mathrm{s}}$ or $\theta_{w}$. The symbol "| |", by which the vector is bounded, represents the magnitude of the vector, which is generally used in vector analysis. $\mathbf{R}$ was given by equation 6 , and its component functions were given in equations 7, 8, and 9. $\mathbf{P}$ was given by equation 14, and its component functions were given in equations 24,25 , and 26.

\section{Curvature of single helical wires:}

$$
\kappa_{\mathrm{s}}=\frac{\left|\mathbf{R}^{\prime} \times \mathbf{R}^{\prime \prime}\right|}{\left|\mathbf{R}^{\prime}\right|^{3}}
$$

Curvature of double helical wires:

$$
\kappa_{\mathrm{w}}=\frac{\left|\mathbf{P}^{\prime} \times \mathbf{P}^{\prime \prime}\right|}{\left|\mathbf{P}^{\prime}\right|^{3}}
$$

Substituting the first and second derivatives of each vector intoequations 29 and 30 and performing the cross and dot products and other operations, the expanded forms of these equations expressed in terms of the component functions are shown below.
Expanded curvature equation for single helical wires:

$$
\kappa_{\mathrm{s}}=\frac{\sqrt{\left(\mathrm{y}_{\mathrm{s}}^{\prime} \mathrm{z}_{\mathrm{s}}^{\prime \prime}-\mathrm{z}_{\mathrm{s}}^{\prime} \mathrm{y}_{\mathrm{s}}^{\prime \prime}\right)^{2}+\left(\mathrm{z}_{\mathrm{s}}^{\prime} \mathrm{x}_{\mathrm{s}}^{\prime \prime}-\mathrm{x}_{\mathrm{s}}^{\prime} \mathrm{z}_{\mathrm{s}}^{\prime \prime}\right)^{2}+\left(\mathrm{x}_{\mathrm{s}}^{\prime} \mathrm{y}_{\mathrm{s}}^{\prime \prime}-\mathrm{y}_{\mathrm{s}}^{\prime} \mathrm{x}_{\mathrm{s}}^{\prime \prime}\right)^{2}}}{\left[\sqrt{\left(\mathrm{x}_{\mathrm{s}}^{\prime}\right)^{2}+\left(\mathrm{y}_{\mathrm{s}}^{\prime}\right)^{2}+\left(\mathrm{z}_{\mathrm{s}}^{\prime}\right)^{2}}\right]^{3}}
$$

Aftersubstituting the functions intoequation 29a, itcan be reduced to its simplest form, as shown in equation $29 \mathrm{~b}$. This expression indicates that the curvature of a single helical wire is independent of the angle of strand rotation and is constant for a given helix angle.

$$
\kappa_{\mathrm{s}}=\frac{\cos ^{2}\left(\alpha_{\mathrm{s}}\right)}{\mathrm{r}_{\mathrm{s}}}
$$

Expanded curvature equation for double helical wires:

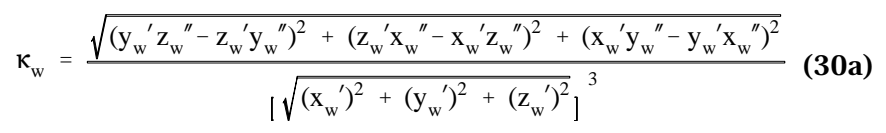

The curvatures were computed for both single and double helical wires in a $6 \times 19$ Seale wire rope. The results for single helical wires are shown in table 4 . The results for double helical wires are shown in table 5 , with the absolute value of $\theta_{w}$ increasing from $0^{\circ}$ to $360^{\circ}$ at increments of $15^{\circ}$.

The curvatures of the IWRC and S3 helical wires were plotted against the absolute value of the angle of strand or wire rotation. Their relationships are shown in figure 15 for two periods. They indicate that (1) the curvature of single helical wires is independent of the angle of strand rotation, as expressed by equation $29 \mathrm{~b}$, (2) the curvature of double helical wires is a periodical function of the angle of wire rotation with a period of $360^{\circ}$, and (3) the curvature of double helical wires is at maximum when the wires are farthest from the rope center and at minimum when the wires are nearest to the rope center because the angle of wire rotation is measured from the positive U-axis, which points away from the rope center, as shown in figure 5 .

Table 4.CCurvature and torsion of single helical wires

\begin{tabular}{ccc}
\hline Wre & $\begin{array}{c}\text { Curvature, } \\
1 / \mathrm{mm}\end{array}$ & $\begin{array}{c}\text { Torsion, } \\
1 / \mathrm{mm}\end{array}$ \\
\hline W11 $\ldots \ldots$ & 0.0513 & 0.1753 \\
W20 $\ldots \ldots$ & 0.0252 & 0.0724 \\
W30 $\ldots \ldots$ & 0.0100 & 0.0179 \\
\hline
\end{tabular}


Table 5.CCurvature and torsion of double helical wires

\begin{tabular}{|c|c|c|c|c|c|c|}
\hline \multirow{2}{*}{$\begin{array}{l}\text { Angle of } \\
\text { wire } \\
\text { rotation, }{ }^{\circ}\end{array}$} & \multicolumn{3}{|c|}{ Curvature, $1 / \mathrm{mm}$} & \multicolumn{3}{|c|}{ Torsion, $1 / \mathrm{mm}$} \\
\hline & W21 & W31 & W32 & W21 & W31 & W32 \\
\hline $0 \ldots$ & 0.0652 & 0.0202 & 0.0265 & 0.1249 & -0.0198 & -0.0268 \\
\hline 15 & 0.0649 & 0.0201 & 0.0264 & 0.1256 & -0.0200 & -0.0273 \\
\hline 30 & 0.0638 & 0.0197 & 0.0260 & 0.1277 & -0.0207 & -0.0288 \\
\hline 45 & 0.0620 & 0.0190 & 0.0254 & 0.1313 & -0.0218 & -0.0314 \\
\hline 60 & 0.0593 & 0.0180 & 0.0244 & 0.1365 & -0.0233 & -0.0353 \\
\hline 75 & 0.0559 & 0.0167 & 0.0232 & 0.1435 & -0.0254 & -0.0407 \\
\hline 90 & 0.0517 & 0.0151 & 0.0216 & 0.1528 & -0.0281 & -0.0479 \\
\hline 105 & 0.0467 & 0.0132 & 0.0197 & 0.1653 & -0.0319 & -0.0580 \\
\hline 120 & 0.0411 & 0.0110 & 0.0175 & 0.1829 & -0.0377 & -0.0723 \\
\hline 135 & 0.0353 & 0.0086 & 0.0152 & 0.0286 & -0.0485 & -0.0933 \\
\hline 150 & 0.0297 & 0.0060 & 0.0130 & 0.2460 & -0.0757 & -0.1234 \\
\hline 165 & 0.0254 & 0.0033 & 0.0113 & 0.2914 & -0.1897 & -0.1586 \\
\hline 180 & 0.0238 & 0.0016 & 0.0106 & 0.3157 & -0.7359 & -0.1768 \\
\hline 195 & 0.0254 & 0.0033 & 0.0113 & 0.2914 & -0.1897 & -0.1586 \\
\hline 210 & 0.0297 & 0.0060 & 0.0130 & 0.2460 & -0.0757 & -0.1234 \\
\hline 225 & 0.0353 & 0.0086 & 0.0152 & 0.2086 & -0.0485 & -0.0933 \\
\hline 240 & 0.0411 & 0.0110 & 0.0175 & 0.1829 & -0.0377 & -0.0723 \\
\hline 255 & 0.0467 & 0.0132 & 0.0197 & 0.1653 & -0.0319 & -0.0580 \\
\hline 270 & 0.0517 & 0.0151 & 0.0216 & 0.1528 & -0.0281 & -0.0479 \\
\hline 285 & 0.0559 & 0.0167 & 0.0232 & 0.1435 & -0.0254 & -0.0407 \\
\hline 300 & 0.0593 & 0.0180 & 0.0244 & 0.1365 & -0.0233 & -0.0353 \\
\hline 315 & 0.0620 & 0.0190 & 0.0254 & 0.1313 & -0.0218 & -0.0314 \\
\hline 330 & 0.0638 & 0.0197 & 0.0260 & 0.1277 & -0.0207 & -0.0288 \\
\hline 345 & 0.0649 & 0.0201 & 0.0264 & 0.1256 & -0.0200 & -0.0273 \\
\hline 360 & 0.0652 & 0.0202 & 0.0265 & 0.1249 & -0.0198 & -0.0268 \\
\hline
\end{tabular}

The torsion at a certain point of a curve measures the degree of twisting of a curve at that point. The change of torsion in a wire is produced by twisting moments that act on the wire cross section. Angular deformation between cross sections results in shearing stresses.

The first derivative of $\mathbf{b}$ in the moving trihedral, as shown in figure 14, with respect to arc length of a curve will yield a vector that is parallel to nand can be expressed as $-\tau \mathbf{n}$. The scalar multiplier $\tau$ is called the torsion of the curve. It measures the rate at which the centroidal axis of either a single or a double helical wire twists out of its osculating plane, which is the plane containing the unit tangent and the unit principal normal vectors. The torsion of a straight line is defined to be zero. If the curve is a plane curve, the torsion is always zero, because the osculating plane is the plane of the curve and the unit binormal vector is constant.

Basicformulas derived for computation of torsion are expressedin terms of the position vector with arc length as the parameter[Sokolnikoff and Redheffer 1958]. To directly apply the models developed in this report, it is more convenient to use equatioßs and 32 for computation of the torsion [Stewart 1991].

Torsion of single helical wires:

$$
\tau_{\mathrm{s}}=\frac{\mathbf{R} \times \mathbf{R}^{\prime \prime} \mathbf{R}}{\left|\mathbf{R} \times \mathbf{R}^{\prime \prime}\right|^{2}}
$$

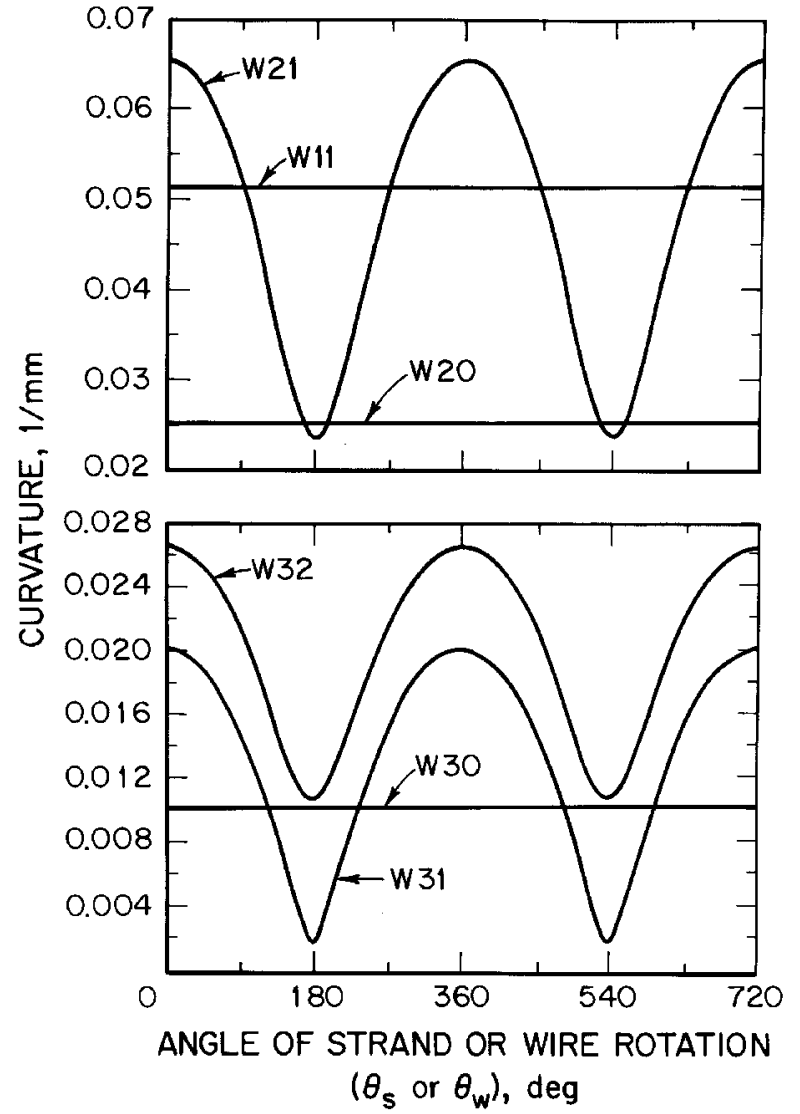

Figure 15.Curvature of IWRC and S3 wires. 
Torsion of double helical wires:

$$
\tau_{\mathrm{w}}=\frac{\mathbf{P}^{\prime} \times \mathbf{P}^{\prime \prime} \mathbf{P}}{\left|\mathbf{P}^{\prime} \times \mathbf{P}^{\prime \prime}\right|^{2}}
$$

Substitutingthe derivatives of each vector into the equationsand performing the cross and dot products and other operationsthe expanded forms of these equations expressed in terms of the component functions are shown below.

Expanded torsion equation for single helical wires:

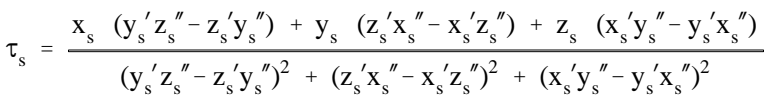

After substituting the functions into equation $31 \mathrm{a}$, it can be reduced to its simplest form, as showequation $31 \mathrm{~b}$. It indicatesthat the torsion of a single helical wire is independent of the angle of strand rotation and is constant for a given helix angle.

$$
\tau_{\mathrm{s}}=\frac{\sin \left(\alpha_{\mathrm{s}}\right) \cos \left(\alpha_{\mathrm{s}}\right)}{\mathrm{r}_{\mathrm{s}}}
$$

Expanded torsion equation for double helical wires:

$\tau_{\mathrm{w}}=\frac{\mathrm{x}_{\mathrm{w}}\left(\mathrm{y}_{\mathrm{w}}{ }^{\prime} \mathrm{z}_{\mathrm{w}}{ }^{\prime \prime}-\mathrm{z}_{\mathrm{w}} \mathrm{y}_{\mathrm{w}}{ }^{\prime \prime}\right)+\mathrm{y}_{\mathrm{w}}\left(\mathrm{z}_{\mathrm{w}}{ }^{\prime} \mathrm{x}_{\mathrm{w}}{ }^{\prime}-\mathrm{x}_{\mathrm{w}}{ }^{\prime} \mathrm{z}_{\mathrm{w}}{ }^{\prime \prime}\right)+\mathrm{z}_{\mathrm{w}}\left(\mathrm{x}_{\mathrm{w}} \mathrm{y}_{\mathrm{w}}{ }^{\prime \prime}-\mathrm{y}_{\mathrm{w}}{ }^{\prime} \mathrm{x}_{\mathrm{w}}{ }^{\prime \prime}\right)}{\left(\mathrm{y}_{\mathrm{w}}{ }^{\prime} \mathrm{z}_{\mathrm{w}}{ }^{\prime \prime}-\mathrm{z}_{\mathrm{w}}{ }^{\prime} \mathrm{y}_{\mathrm{w}}{ }^{\prime \prime}\right)^{2}+\left(\mathrm{z}_{\mathrm{w}} \mathrm{x}_{\mathrm{w}}{ }^{\prime \prime}-\mathrm{x}_{\mathrm{w}}{ }^{\prime} \mathrm{z}_{\mathrm{w}}{ }^{\prime \prime}\right)^{2}+\left(\mathrm{x}_{\mathrm{w}}{ }^{\prime} \mathrm{y}_{\mathrm{w}}{ }^{\prime \prime}-\mathrm{y}_{\mathrm{w}}{ }^{\prime} \mathrm{x}_{\mathrm{w}}{ }^{\prime \prime}\right)^{2}}$

The torsions of both single and double helical wires in a $6 \times 19$ Seale wire rope were computed. The results for single helical wires are shown in table 4 . The results for double helicalwires are shown in table 5, with the absolute value of $\theta_{\mathrm{w}}$ increasing from $0^{\circ}$ to $360^{\circ}$ at increments of $15^{\circ}$. The negativetorsions for $\mathrm{W} 31$ and $\mathrm{W} 32$ represent the twisting of thecentroidal axes of these wires in a left lay strand, where the twisting is opposite in direction to that in a right lay strand.
The torsions of the IWRC and S3 helical wires were plottedagainst the absolute value of the angle of strand or wire rotation. Their relationships are shown in figure 16 for two periods. They indicate that (1) the torsion of single helical wires is independent of the angle of strand rotation, as expressedby equation $31 \mathrm{~b}$, (2) the torsion of double helical wiresis a periodical function of the angle of wire rotation with a period of $360^{\circ}$, and (3) the torsion of double helical wires is at minimumwhen the wires are farthest from the rope center andat maximum when the wires are nearest to the rope center. It is also noted that the minimum torsion occurs at the locations where the curvature is at maximum, and the maximum torsion occurs at the locations where the curvature is at minimum.

\section{ANALYSIS OF DEFORMATIONS}

When a tensile load is applied to a wire rope, each individual wire will deform. Because of the differences in the wire lengths and the helix angles of single and double helical wires, the load will not be distributed among the wires simply based on the cross-sectional areas. The effect of these wire

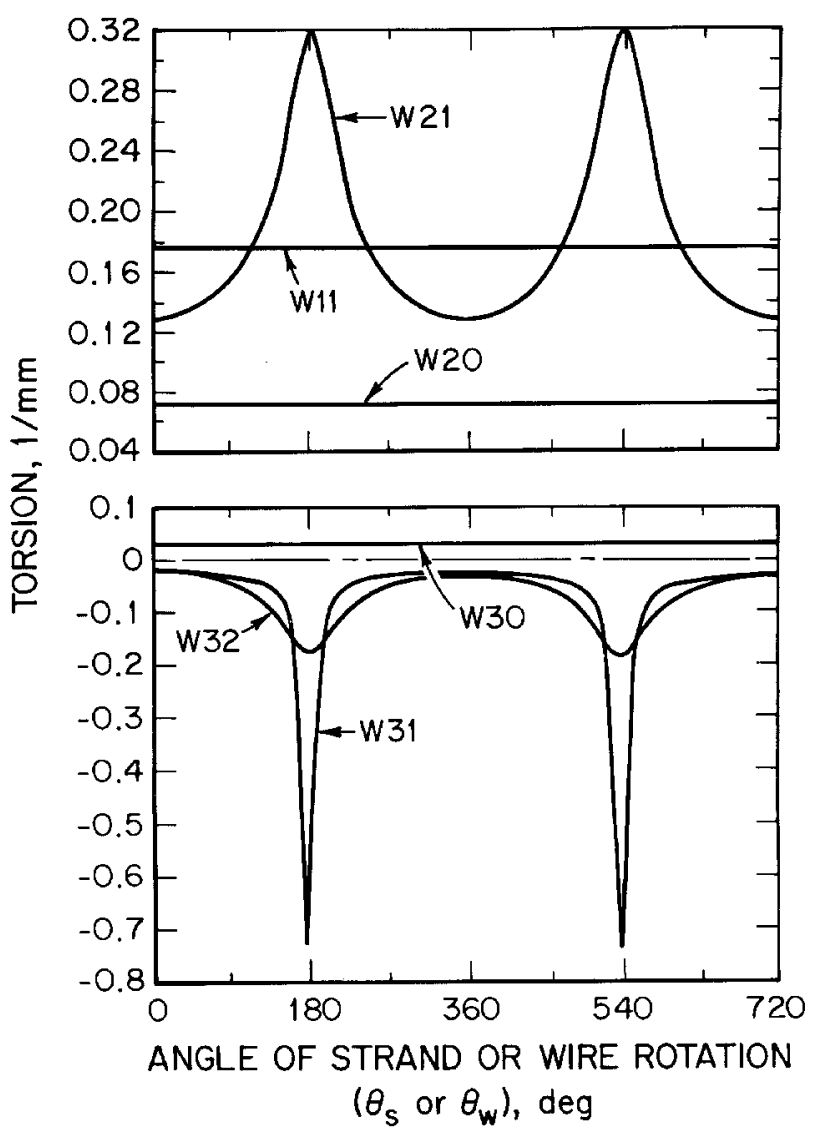

Figure 16:Torsion of IWRC and S3 wires. 
deformationsn the geometry of the rope structure needs to be determine. The major change is axial elongation along the centroidalaxis of a wire. Accompanying the axial elongation is a lateral contraction of the cross section. In addition, bendingand twisting moments are generated in the wire that causechanges in the curvature and torsion of the wire. The combination of all of these individual wire deformations results in the deformation of the rope structure.

There will be a resultant twisting moment, which will cause the rope to rotate if the ends are not restrained. Therefore,deformation of the rope structure will depend on whetherthe rope is allowed to rotate or not. In mine hoisting, the cage or skip and rope are prevented from rotating by the shaftguides. Some rope manufacturers also produce rotationresistantrope [Wire Rope Technical Board 1993], which is made with layers of strands laid in opposite directions to producecounteracting torques. In the use of rope with both endsrestrained, the total number of strand lays and the total numberof wire lays in a rope are kept constant. Thus, the relative rotation, $\mathrm{n}$, included in thøodels for double helical wires,remains constant as the rope structure deforms under load. Because of the objective of evaluating the retirement criteria fomine hoists, only the restrained-rotation case will be considered in this report.

\section{Axial Elongation and Lateral Contraction}

The axial elongation and lateral contraction of the wires will occur simultaneously when the rope is under tension. Neithercan be determined independently. However, a sufficient number of equations may be established to obtain the solutionsfor a given rope strain. The structural parameters of the deformed rope used in deriving the required equations are the path length of the wire in each lay of the deformed strand, the wire strain, the reduced wiralius, and the radius of the deformedhelix. Each of them is described below. The symbolsused are the same as those defined previously, except that the subscript "d" has been added to represent their values in the deformed rope structure. The variable used to specify the axial elongation of the rope is the rope strain, which is representedy $\epsilon_{\mathrm{r}}$ in the equations. It is determined by dividing the amount of elongation of the rope by the original length before the application of load.

\section{Wire Strain}

Hooke's law states that, within the elastic range, the deformation produced by exterfierces that act on nonrigid bodiesis proportional to the stress. The path lengths of the wire before and after the application of load, therefore, are neededto specify the axial deformation and determine the tensile stress.

To establish the relationship between thegths of wire andrope in the deformed rope structure, the developed views, which are the same as those shownin figure 3 for the undeformed ropewill be used. The only differenceis to replace theoriginal structuralparameterswith the deformedones, i.e., Swith $\mathrm{S}_{\mathrm{r}} \mathrm{S}_{\mathrm{s}}$ with $\mathrm{S}_{\mathrm{sd}}, \mathbf{r}_{\mathrm{s}}$ with $\mathrm{Sd}_{\mathrm{Sd}} \alpha_{\mathrm{s}}$ with $\alpha_{\mathrm{sd}}, S_{\mathrm{w}}$ with $\mathrm{S}_{\mathrm{wd}}, \mathrm{r}_{\mathrm{w}}$ with $\mathrm{wdd}_{\mathrm{wd}}$ and $\alpha_{\mathrm{w}}$ with $\alpha_{\mathrm{wd}}$ When $\theta_{\mathrm{s}}$ $=2 \pi, \mathrm{S}_{\mathrm{rd}}$ becomesthe deformedlay length of strand, which may be expressed as $\underset{\mathrm{S}}{\mathrm{I}}\left(1+\epsilon_{\mathrm{r}}\right)$. On the basis of a single lay of a strand, equations $\mathbf{3 R d} 34$ are obtained for single and double helical wires, respectively. each lay of the strand, a double helical wire has an angle of wire rotation of $\mathfrak{z}$, although the strand only has an angle of strand rotation of 2

Path length of the deformed single helical wire in each l. of strand:

$$
S_{s d}=\sqrt{\left[L_{s}\left(1+\epsilon_{r}\right)\right]^{2}+(2 \pi l}
$$

Path length of the deformed double helical wire in each of strand:

$\sqrt{\left[L_{s}\left(1+\epsilon_{r}\right)\right]^{2}+\left(2 \pi r_{s d}\right)^{2}+(:}$

The wire strain is the change of the path length of a wire, as expressed by equations 35 and 36.

Wire strain for single helical wires:

$$
\epsilon_{S}=\frac{S_{S d}-S_{S}}{S_{S}}
$$

Wire strain for double helical wires:

$$
\epsilon_{w}=\frac{S_{u d}-S_{w}}{S_{w}}
$$

\section{Reduced Wire Radius}

Experiments show that the axial elongation of a wire in tension is always accompanied by lateral contraction of the wire. For any material, the ratio of the unit lateral contraction to the unit axial elongation is known as Poisson's ratio, $\mu$, which is constant within the elastic range. The unit lateral contraction for a round wire is determined by dividing the reduction of the wire radius in the deformed rope structure by the original radius. If $R_{s}$ and $R_{w}$ represent the original wire radii of single and double helical wires, respectively, the reduced wire radii, $R_{s d}$ and $R_{\text {wd }}$ can be expressed in terms of the wire strain $\epsilon_{\mathrm{s}}$ and $\epsilon_{\mathrm{w}}$, respectively, in accordance with the definition of Poisson's ratio. 
Reduced radius of single helical wires:

$$
\mathrm{R}_{\mathrm{sd}}=\mathrm{R}_{\mathrm{s}}\left(1-\mu \epsilon_{\mathrm{s}}\right)
$$

Reduced radius of double helical wires:

$$
\mathrm{R}_{\mathrm{wd}}=\mathrm{R}_{\mathrm{w}}\left(1-\mu \epsilon_{\mathrm{w}}\right)
$$

A Poisson's ratio of 0.303 for steel [Avallone and Baumeister 1986] may be used for determining the reduced wire radius at different wire strains.

\section{Radius of Deformed Helix}

The radius of the deformed helix for single helical wires is a function of thearious reduced wire radii. For example, the radii of the deformed helices for wires W11 and W20, accordirg to figures 6 through 8 , are simply the sum of the various reduced wire radii, as shown below.

Radius of the deformed strand helix for wire W11:

$$
\mathrm{r}_{11 \mathrm{~d}}=\mathrm{R}_{10 \mathrm{~d}}+\mathrm{R}_{11 \mathrm{~d}}
$$

Radiusf the deformed strand helix for wire W2O or strandS2:

$$
r_{20 d}=R_{10 d}+2 R_{11 d}+2 R_{21 d}+R_{20 d}
$$

Theradius of the deformed strand helix for wire W30 or strand S3 cannot be simply expressed as in equations 39 and 40 for wires W11 and W20. It will depend on the radius of the deformedwire helix for wire W32, $r_{32 d}$ which is not merely the sum of the various reduced wire radii. However, both can be related by the following equation.
Radius the deformed strand helix for wire W3O or strandS3:

$$
r_{30 d}=R_{10 d}+2 R_{11 d}+4 R_{21 d}+2 R_{20 d}+R_{32 d}+r_{32 d}
$$

The radius of the deformed wire helix for double helical wiresalso is a function of the various reduced wire radii. For example,the radii of the deformed wire helix for wires W21 and W31, according to figuresr81 9, are simply the sum of the various reduced wire radii, as shown below.

Radius of the deformed wire helix for wire W21:

$$
r_{21 d}=R_{20 d}+R_{21 d}
$$

Radius of the deformed wire helix for wire W31:

$$
\mathbf{r}_{31 \mathrm{~d}}=\mathbf{R}_{30 \mathrm{~d}}+\mathbf{R}_{31 \mathrm{~d}}
$$

Theradius $r_{32 d}$ will be dependent on the location of the contact point, as shown in figure 9, of the adjacent elliptical cross sectionsof wires W31 and W32 in the deformed rope structure. Assuminghat the contact point between the wire $\mathrm{W} 32$ at $\theta_{\mathrm{w}}=$ $-3 \pi / 2 \mathrm{rad}$ and the wire $\mathrm{W} 31$ at $\theta_{\mathrm{w}}=-(3 \pi / 2+\pi / 9) \mathrm{rad}$ is at $\left(u_{c}, v_{c}\right)$ on the U-V plane, which is perpendicular to the centroidalaxis of the deformed strand S3, equations 44 and 45 canbe derived. Equation 44 is obtained from the equations of the two ellipses by letting ${ }_{1}$ of the upper quadranbe equal to $v_{32}$ of the lower quadrants at $u=u_{c}$. Equation 45 is obtained by letting theirespective derivatives be equal, i.e., $\mathrm{dv}_{31} / \mathrm{du}=$ $\mathrm{dv}_{32}$ duat $\mathrm{u}=\mathrm{u}_{\mathrm{c}}$. The equations represent two conditions that $r_{32 d}$ must satisfy.

Radius of the deformed wire helix for wire W32 subject to two conditions:

$$
\begin{gathered}
r_{32 d}-\sqrt{R_{32 d}^{2}-\frac{\left[u_{c} L_{32}\left(1+\epsilon_{30}\right)\right]^{2}}{\left[L_{32}\left(1+\epsilon_{30}\right)\right]^{2}+\left(2 \pi r_{32 d}\right)^{2}}} \\
=\frac{-\left(c_{2} u_{c}+c_{5}\right)+\sqrt{\left(c_{2} u_{c}+c_{5}\right)^{2}-4 c_{3}\left(c_{1} u_{c}^{2}+c_{4} u_{c}+c_{6}\right)}}{2 c_{3}}
\end{gathered}
$$




$$
\begin{gathered}
\frac{\mathrm{u}_{\mathrm{c}}\left[\mathrm{L}_{32}\left(1+\epsilon_{30}\right)\right]^{2}}{\left[\mathrm{~L}_{32}\left(1+\epsilon_{30}\right)\right]^{2}+\left(2 \pi \mathrm{r}_{32 \mathrm{~d}}\right)^{2}} \sqrt{\frac{\left[\mathrm{L}_{32}\left(1+\epsilon_{30}\right)\right]^{2}+\left(2 \pi \mathrm{r}_{32 \mathrm{~d}}\right)^{2}}{\left(\mathrm{R}_{32 \mathrm{~d}}^{2}-\mathrm{u}_{\mathrm{c}}^{2}\right)\left[\mathrm{L}_{32}\left(1+\epsilon_{30}\right)\right]^{2}+\left(2 \pi \mathrm{r}_{32 \mathrm{~d}} \mathrm{R}_{32 \mathrm{~d}}\right)^{2}}} \\
=\frac{1}{2 \mathrm{c}_{3}}\left[-\mathrm{c}_{2}+\frac{\mathrm{c}_{2}\left(\mathrm{c}_{2} \mathrm{u}_{\mathrm{c}}+\mathrm{c}_{5}\right)-2 \mathrm{c}_{3}\left(2 \mathrm{c}_{1} \mathrm{u}_{\mathrm{c}}+\mathrm{c}_{4}\right)}{\sqrt{\left(\mathrm{c}_{2} \mathrm{u}_{\mathrm{c}}+\mathrm{c}_{5}\right)^{2}-4 \mathrm{c}_{3}\left(\mathrm{c}_{1} \mathrm{u}_{\mathrm{c}}^{2}+\mathrm{c}_{4} \mathrm{u}_{\mathrm{c}}+\mathrm{c}_{6}\right)}}\right]
\end{gathered}
$$


Thecoefficients $c_{1}$ through $c_{6}$ in these equations are described by the following expressions, where $\phi=\pi / 9$. The common term in all of the coefficients is, as defined in equation 52.

$$
c_{1}=\cos ^{2}(\phi)+\frac{\sin ^{2}(\phi)}{c_{7}}
$$

$$
\begin{aligned}
& \sin (\phi) \cos (\phi)+\frac{2 \sin (\phi)}{c_{7}} \\
& c_{3}=\sin ^{2}(\phi)+\frac{\cos ^{2}(\phi)}{c_{7}}
\end{aligned}
$$

$4=\frac{-2 \sin (\phi)\left(R_{30 d}+R_{31 d}\right)}{C_{7}}$

$5=\frac{-2 \cos (\phi)\left(R_{30 d}+R_{31 d}\right)}{C_{7}}$

$C_{6}=\frac{\left(R_{30 d}+R_{31 d}\right)^{2}-R_{31 d}^{2}}{C_{7}}$

$\frac{\left[L_{30}\left(1+\epsilon_{r}\right)\right]^{2}+(2 \pi r \Xi}{\left.30\left(1+\epsilon_{r}\right)\right]^{2}+\left(2 \pi r_{3} 0 d\right)^{2}+}$

Because wire W10 is the straight wire of strand S1, the wire strain is identical to the rope strain. Its reduced wire radius, $R_{10 d}$ is simply equivalent to $R_{10}\left(1-\mu \epsilon_{\mathrm{r}}\right)$. The structural parameters in length measurement for the other helical wires are interrelated, as indicated by the equations above. Theycan be determined by solving the required simultaneous equationsfor the wires in each strand. For example, four simultaneousquations, i.e., equations $33,35,37$, and 39 , may be solved for the structural parameters of wire W11 under a certainrope strain. Once the structural parameters of the wires in strand $\mathrm{S} 1$ in the deformed rope become known, the structuraparameters of the wires in strand S2 under the same rope strain can be determined by solving eight simultaneous equationsi.e., equations 33, 35, and 37 written for wire W20 withequation 40 and equations 34,36 , and 38 written for wire W21 with equation 42 . Using the solutions obtained for the wiresin strands S1 and S2, the structural parameters of the wires in strand S3 under the same rope strain can be determined by solving 20 simultaneous equations, i.e., equaions 33, 35, and 37 written for wire W30 with equation41; equations 34,36 , and 38 written for wire W31 withequation 43; and equations 34,36 , and 38 written for wire W32 with equations 44 through 52.

\section{Angle of Deformed Helix}

When the rope elongates under tensile load and is restrainedfrom rotating, the angles of the strand and wire helices will also change because of the axial elongation and lateral contractionof the wire. Using figure 3 , the relationship betweenthe angle of the deformed strand or wire helix and the rope strain $\epsilon_{\mathrm{r}}$, is given in the following equations.

\section{Angle of the deformed strand helix:}

If the original $\alpha_{\mathrm{s}}$ is less than $\pi / 2 \mathrm{rad}$, then

$$
\alpha_{\text {sd }}=\tan ^{-1}\left[\frac{L_{s}\left(1+\epsilon_{r}\right)}{2 \pi r_{s d}}\right.
$$

If the original $\alpha_{\mathrm{s}}$ is greater than $/ 2 \mathrm{rad}$, then

$$
\alpha_{s d}=\pi-\tan ^{-1}\left[\frac{L_{s}\left(1+\epsilon_{r}\right)}{2 \pi r_{s d}}\right.
$$

Angle of the deformed wire helix:

If the original $\alpha_{\mathrm{w}}$ is less than $/ 2 \mathrm{rad}$, then

$$
n d=\tan ^{-1} \sqrt{\frac{\left[L_{s}\left(1+\epsilon_{r}\right)\right]^{2}+\left(2 \pi r_{s d}\right)}{\left(2 \pi n r_{n d}\right)^{2}}}
$$

If the original $\alpha_{\mathrm{w}}$ is greater than $/ 2 \mathrm{rad}$, then

$n d=\pi-\tan ^{-1} \sqrt{\frac{\left[L_{s}\left(1+\epsilon_{r}\right)\right]^{2}+\left(2 \pi r_{s d}\right.}{\left(2 \pi n r_{n d}\right)^{2}}}$

Usingthe radii of the deformed helix determined previously, the angle of the deformed helix for single helical wires, $\alpha_{\mathrm{sd}}$, can be calculated with either equation 53 or 54 , depending on whetherthe original angle, $\alpha_{\mathrm{s}}$, is less than or greater than $\pi / 2$. Similarly,the angle of the deformed helix for double helical wires, $\alpha_{w d}$ can be calculated with either equation 55 or 56 , also dependingon whether the original angle, $\alpha_{w}$, is less than or greaterthan $\pi / 2$. The lay length of strand, $L_{s}$, in these equations is the original lay length.

The model for the deformed wire rope can now be constructed by replacing the structural parameitethe original modelwith the deformed ones obtained from the analysis of deformations shown above. 


\section{Bending and Twisting}

To determine the bending and twisting of the wires, the curvaturand torsion of the deformed wires must be evaluated. The equations required for evaluation are the same as those derivedearlier, except that the structural parameters of the deformed rope or the component functions of the deformed modelmust now be used in equations $29 \mathrm{~b}$ and $31 \mathrm{~b}$ for single helical wires and equations $30 \mathrm{a}$ and $32 \mathrm{a}$ for double helical wires.

If $\kappa_{\mathrm{sd}}$ and $\kappa_{\mathrm{wd}}$ represent the curvatures of the deformed single and double helical wires, respectively, then bending maybe expressed as $\left(\kappa_{\mathrm{sd}}-\kappa_{\mathrm{s}}\right)$ or $\left(\kappa_{\mathrm{wd}}-\kappa_{\mathrm{w}}\right)$. Similarly, if $\tau_{\mathrm{sd}}$ and $\tau_{\mathrm{wd}}$ representthe torsions of the deformed single and double helical wires, respectively, thewisting may be expressed as $\left(\tau_{\mathrm{sd}}-\tau_{\mathrm{s}}\right)$ or $\left(\tau_{\mathrm{wd}}-\tau_{\mathrm{w}}\right)$. As indicated by equations $29 \mathrm{~b}$ and $31 \mathrm{~b}$, both the curvature and torsion of the deformed single helical wires also will bindependent of the angle of strand rotation. Thereforeboth the bending and twisting of single helical wires would be uniform along their entire paths when a load is applied. Both the curvature and torsion of the deformed doublehelical wires are periodical functions of the angle of wire rotation. The period is $2 \pi$, just as shown in figures 15 and 16 for the undeformed double helical wires.

\section{CONCLUSIONS}

Themodel developed in this report fully describes the geometry of the structure of wire ropes of any round-strand construction. It is expressed by vector equations in a threedimensional,right-handed, rectangular Cartesian coordinate systemand is general enough that any combination of wire and strandlay directions can be handled if the stated sign conventionsfor the angles of strand and wire rotation and the relative rotation are followed in the component functions.

The wire paths are defined for the first time by using a developedmodel, which not only reveal the shapes of the various wires, but also are useful for predicting damage patternsthrough external and internal wear. The geometric properties of each wire can be easily evaluated by using this model. A 33-mm 6×19 Seale, IWRC, right regular lay wire rope was analyzed to illustrate the model's usefulness.
A system of equations was also established for determininghe structural parameters of the deformed rope at a given rope strain, with restrained ends, thus obtaining the modelfor the deformed rope. The geometric properties of eachdeformed wire can be evaluated the same way as shown in this report for the undeformed rope.

It is recommended fonture work that stress analysis be conductedbased on the changes of these geometric properties of the deformed wires to determine how the load is distributed among these wires. Furthermore, the model could be used to studythe effect of wear and breaking of wires on strength loss for the various round-strand wire ropes used in mine hoisting so that more scientifically based retirement criteria can be established.

\section{REFERENCES}

Avallone EBaumeister T III, eds. [1986]. Marks' standard handbook formechanical engineers. 9th ed. New York, NY: MbGraw-Hill Book Co. p. 5-16.

CFRCode of Federal regulaWbashington, DC:Gorsmment Printing Office, Office of the Federal Register.

CostellGA [1990]. Theory of wire rope. New York, NY: SpringerVerlag, pp. 53-54.

LeeWK [1991]. An insight into wire rope geometry. Int J Solids Structures8(4):471-490.
Leitholl [1986]. The calculus with analytic geometry. 5th ed. New York, NY: Harper \& Row, Publishers, Inc., pp. 1072-1077. Sokolnikoff IS, Redheffer RM[1958]. Mathematics of physics and modem engineering. New York, NY: MoGraw-Hill BookCo.,Inc., pp. 311-315. Stewart [1991]. Calculus. 2nd ed. Pacific Grove, CA: Brooks/Cole Publishing Co., pp. 688-691.

WirdRope Technical Board [1993]. Wire rope users manual. 3rd ed. Woodstock, MD: Wire Rope Technical Board. 


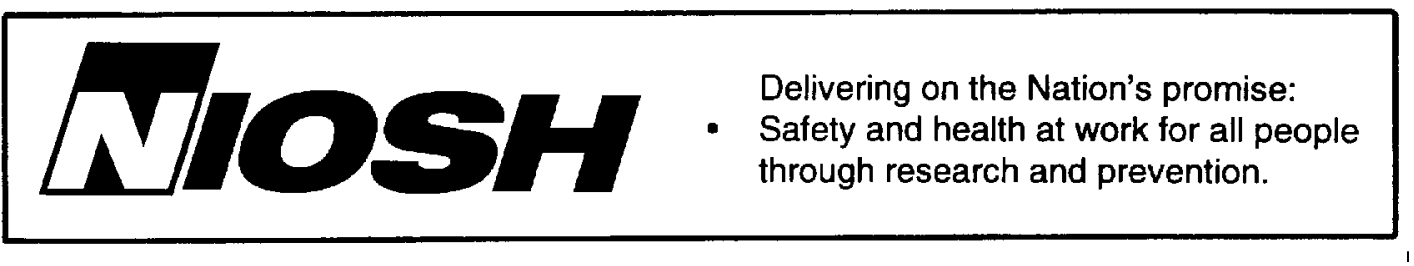

To receive other information about occupational safety and health problems, call 1-800-35-NIOSH (1-800-356-4674), or visit the NIOSH Home Page on the World Wide Web at http://www.cdc.gov/niosh

DHHS (NIOSH) Publication No. 98-148

September 1998 